\title{
The contingency theory of management accounting and control: $1980-2014$
}

\author{
David Otley \\ Distinguished Professor of Accounting \& Management (Emeritus) \\ Lancaster University Management School \\ Lancaster LA1 4YX, UK \\ [e-mail: d.otley@lancaster.ac.uk ]
}

\begin{abstract}
This article reviews the literature on the contingency theory of management accounting since the 1980 review by the author. It traces the expansion of this literature and critically outlines some of the major themes explored over this period. It argues that a mechanistic approach that will develop into a predictive mechanism for the design of optimal control systems is misguided. Rather the existence of management control 'packages' that are continually changing and developing requires studies that follow these changes over time and seek to explain the mechanisms that are observed to be deployed. The 'package' concept has not yet been taken seriously in the design of most empirical studies although this is fundamental to the design of future studies. That is, different elements of control system packages are developed quasi independently by different actors at different times and are only loosely co-ordinated. Full coordination is precluded for several reasons, most notably the rapid pace of change and the addition of new or amended systems at a faster rate than the coordination process can develop. It is suggested that the narrow view of contingency that relies on responses to generally applicable questionnaires needs to be replaced by a more tailored approach that takes into account the context of specific organizations.
\end{abstract}

Keywords

Management control package

Contingency theory

Management control system

Middle range theory

Knowledge in management accounting 


\section{The contingency theory of management accounting and control: $1980-2014$}

\section{Introduction}

This paper provides an overview of the research on management accounting and control which has used a contingent perspective. It starts from my 1980 review of the topic (Otley, 1980) and seeks to bring this up to the present day ${ }^{1}$. However, there are a number of features that require clarification to define the scope of this review. First, the topic has broadened in its scope over the last three decades and it seems sensible to include aspects of management control systems (MCSs) which are used in conjunction with management accounting information rather than focussing solely on management accounting techniques. Second, management accounting has itself changed with a variety of 'new' techniques being developed and popularised, particularly in the 1980s and 1990s. Third, organizations have changed with traditional hierarchical forms being modified into flatter forms, and strategies which emphasize concentrating on a core business rather than attempting to encompass the whole supply chain within a single legal entity. Thus control systems are increasingly required to operate across organizational boundaries. Finally, the idea of contingency requires further clarification, as it can be argued that all research on these topics has to take a 'contingency' approach as it becomes recognized that universal solutions to problems in organizational control generally do not exist.

In the 1970s management accounting formed the centrepiece of many organizational decision-making and control approaches. Budgetary control was the dominant technique used and most of the early contingency-based research studies concentrated on the deployment and use of budgets. Indeed many of the early studies exposed the flaws that budgetary information possessed when used in a manner that did not acknowledge its limitations. More recently non-financial performance measures have increased in popularity and are seen as part of an overall control system, together with a variety of other control approaches which have little to do with traditional management accounting. For this paper it seems most appropriate to concentrate on the over-arching area of management control systems where much of the research takes an organizational approach. Decision-making, by contrast, tends to take an individual approach informed predominantly by psychology

\footnotetext{
${ }^{1}$ From this point on I will refer to my own papers in the third person and put any personal comments in a footnote.
} 
and this is covered in a separate review by Hall (2016) in this issue. However, the boundary is not always clear as some studies use both individual and organizational level variables, and focus on topics which include both decision-making and control, so there is some overlap.

The developments in management accounting began with the introduction of ActivityBased Costing (ABC) in the early 1980s, although this concentrated on generating information for improved decision-making rather than control. However, it was rapidly followed by other techniques often lumped together under the general heading of strategic management accounting. Although this can be interpreted as an attempt by management accountants to maintain their presence at the centre of both organizational decision-making and control, it is also a convenient label to encapsulate the approaches that were developed during this decade. However, the dominance of accounting control was challenged in the early 1990s by the codification of what has become the most widely adopted technique in modern organizations, the Balanced Scorecard (BSC), which combined both financial and non-financial performance measures into a single integrated framework. The scope of management control increasingly began to include issues of both strategic and operational control that had been specifically excluded (for reasons of simplicity and convenience) by Anthony (1965) in his seminal definition of the field.

The context in which management accounting and control is practised has also undergone substantial change. Organizations have become less hierarchical and many have restructured themselves to focus on their 'core businesses', leaving more peripheral activities to be outsourced. Thus organizations now tend to be embedded into supply chains and new forms of control need to be developed in this situation (Anderson and Dekker, 2014) ${ }^{2}$. These supply chains span several different legal entities with no hierarchical oversight, although there is often one large organization that dominates the other participants. These developments were reviewed in Otley (1994) but have continued to change subsequently. In particular, the general business environment has shown an increasing rate of change and competition, both locally and globally, which has caused a greater degree of uncertainty to become apparent. Finally, technological developments continue to drive change at an increasing rate, not least in the changes to business practice which have been made available by modern computer technology and the internet. At the very least this has

\footnotetext{
${ }^{2}$ See also Dekker in this issue.
} 
led to increased environmental uncertainty and a breakdown in the (often implicit) predictive models on which control was based.

The idea of the role of contingency theory is also beginning to change. Whereas initially it developed from the idea that no universal solution to the problems of control was feasible, it hoped that empirical work would establish the key contingencies from which prescriptions to suit different sets of circumstance could be developed. However, research over the past four decades has come up with an extended list of possibly significant contingencies that are faced by organizations, many of which suggest conflicting recommendations. Even if research could be progressed on a much greater scale than in the past, it is unlikely that an overall contingency model could be developed to suggest optimal control configurations in all possible combinations of circumstances. And even if was to prove possible, the world would have moved on by the time the results were available. Contingency therefore has to be considered in a much more dynamic context than previously, which leads to the need to use more process-based models which examine the mechanisms of change and the implementation of modified forms of management and control.

This paper will therefore not attempt to perform a comprehensive review of all previous 'contingency' studies, of which there have been a number, most notably that by Chenhall (2007) which updates his 2003 review and this paper will not attempt to duplicate the detailed work he performs in that comprehensive chapter. Chenhall noted that "the term contingency means that something is true only under specified conditions. As such there is no 'contingency theory', rather a variety of theories may be used to explain and predict the conditions under which particular MCSs will be found or whether they will be associated with enhanced performance." (p. 191) He goes on to suggest that a much wider range of theories may prove useful, encompassing economics (both agency approaches and behavioural economics), psychology, sociology and information science. He also suggests that prior work has concentrated on traditional, functionalist theories and should move on to use more interpretive and critical views in future. This paper will analyse a number of practical and conceptual issues that appear to make it likely that traditional approaches to contingent theorisations have run their course and to argue that it will require different approaches to provide insightful and useful explanations of this complex subject. 


\section{What is contingency theory?}

The idea of a contingency theory of management accounting began to develop in the 1970 s in an attempt to explain the varieties of management accounting practice that were apparent at that time. It drew heavily on the contingency theory of organizational structure which had been developed over the previous twenty years to codify which forms of organizational structure were most appropriate to specific circumstances. The independent variables used to explain organizational structure were often transferred wholesale into the emerging theory of management accounting to explain the design and use of management accounting systems, with additional variables being added as the years progressed ${ }^{3}$. As Hopwood (1974) had pointed out earlier, the design of a (management accounting) system and the design of an organizational structure are really inseparable and interdependent, although this important observation has tended to be neglected over the years that followed.

In his overview of the contingency theory of management accounting, Otley (1980) specifies that "a contingency theory must identify specific aspects of an accounting system which are associated with certain defined circumstances and demonstrate an appropriate matching." (p.413). This indicates three areas to which attention needs to be paid. First, what are the aspects of the management accounting system that are to be explained? In particular, are we concerned just with the existence of specific techniques in an organization, or also with the extent and manner of their use? Studies have tended to be rather arbitrary in their selection of the techniques they focus on, with little consistency between one study and another both in selection and measurement of variables connected with the accounting control system. Second, how are the defined circumstances to be selected? Again, although the contingent variables used by organization theorists have been extensively used here, often only a subset are used in any one study making comparability difficult. Finally, the definition of what constitutes an appropriate matching has caused significant difficulty over the years. At its most simple, existence has been taken as indicating such a matching, although this assumes that a long-run equilibrium has been achieved. More sophisticated studies have used some variant of firm performance to indicate whether an appropriate matching has been found, despite the likelihood that

\footnotetext{
${ }^{3}$ This led to an ambiguity in the role of organizational structure which was the dependent variable in the organizational theory, but an independent variable in the management accounting theory, if it was included. Evidently a risk of multicollinearity could exist if it was used together with the common list of explanatory variables.
} 
MCSs have only a small impact on performance, although the measures used vary. In addition, use of performance in this way is potentially problematic as it can be argued that performance is also an independent contingent variable in its own right which can explain the extent to which reliance is placed on accounting systems in an organization.

However, the totality of these extended approaches implies a very broad definition of contingency theory, which led to Chenhall's (2007) previously quoted comment that there are inevitably a range of contingency theories. Indeed, it might be suggested that all research in management accounting is essentially contingent, in that it seeks to discover when specific techniques might be most appropriate for particular organizations in their specific circumstances. Clearly, given this possibility a overall review needs to be bounded, and initially a simple approach to what is included and excluded was taken to indicate some of the broad trends that have occurred over the period since $1980^{4}$, but confined to those studies which make a specific reference to 'contingency', or which can be clearly seen as having such a focus.

\section{A survey $1980-2014$}

An initial literature search was conducted using three steps. Firstly, a preliminary list was generated by searching key words in the online versions of seven major accounting journals. Secondly, a further search was conducted using major electronic databases which provide access to most of the other important journals. Finally, the list was further supplemented by examining the reference lists of the key articles already identified. This was intended to generate a list of relevant articles that was as complete as possible in the area of contingent approaches to management accounting and control.

The literature research began by searching articles from major relevant journals. namely the following nine major accounting journals: Accounting, Organizations and Society, British Accounting Review, European Accounting Review, Management Accounting Research, Journal of Management Accounting Research, Accounting Auditing and Accountability Journal, The Accounting Review, Journal of Accounting Research, and Accounting and Business Research. As all of these journals provide online resources, articles were collected by key word searching on the supporting

\footnotetext{
${ }^{4}$ But see Speklé \& Kruis (2014) for an up to date review of recent developments in the management control literature more widely.
} 
online platform. The key words used were "contingency", "contingent", "management", "management accounting" "relation", "relationship", "impact", "effect", and "influence". The last five words are searched in order to include the essentially contingency studies which do not directly claim to be studies related to contingency theory. The time specified in the search filter spanned from 1980 to mid-2014. The articles generated were reviewed by title and abstract to ensure that they were appropriate. As some cross-disciplinary studies may be published in the journals of other fields a more general search with similar filter conditions was conducted on the seven major platforms which provide access to multidisciplinary collection of online resources, namely Science Direct Freedom Collection, Business Source Premier, ProQuest, Wiley Online Library, SwetsWise, JSTOR and Taylor \& Francis Social Science and Humanities Library. In the final step, the reference lists in the review articles identified and the most cited articles thus listed were used to add to the overall list, although this generated only a small number of additions, giving some confidence in the completeness of the list. This process generated an extensive list which was only lightly edited to exclude items which seemed clearly inappropriate. The final list may therefore include some items of peripheral relevance, but it was considered more useful to err on the side of inclusion rather than exclusion.

In summary, the number of articles from each journal is shown as table 1, with only the accounting journals which contain more than four articles being included ${ }^{5}$. It is notable that, although a reasonable number of authors were located in the USA, the main journals in which this work was published are European- or Australasian-based, rather than US-based. This probably indicates the US journal preference for quantitative work using substantial (often publicly available) data sets and the use of sophisticated quantitative models. Most work in this field requires data to be collected individually (rather than there being any publicly available datasets) which restricts samples to a quite small size (rarely more than the low hundreds), and thus precludes the extensive use of the more data hungry statistical techniques ${ }^{6}$.

\{Table 1 and Figure 1 about here\}

\footnotetext{
${ }^{5}$ Just four relevant articles were found in each of The Accounting Review and the Journal of Accounting Research in the period covered.

${ }^{6}$ Recent developments in statistical techniques now permit smaller sample sizes to generate reliable results, and may allow more useful statistical work to be conducted in this field in future.
} 
The total number of articles included in the bibliography amounted to 236 . Of these 157 could be categorized as being empirical and using quantitative methods ${ }^{7}$; the remainder were either theoretical (39), review (20), qualitative (10), or methodological (10), although several articles could have been included in more than one category. In the 1980s, less than 5 relevant articles were published each year although this figure increased to around 10 in late 1990s. Despite a brief drop of publications in years 2000 and 2001, the statistics show a generally upward trend, as shown In Figure 1 below, and indicate the steadily growing amount of work on this topic over the period. However, this increase may be partly due to the increased number of journals available, most notably the launch of Management Accounting Research in 1990.

\section{Initial overview}

There are a number of features that characterise the bulk of the work reviewed. First, it is generally not systematic, and the variables (or measures) selected for analysis in any particular study generally do not exactly correspond to those used in prior work. Thus, cumulative results are rare. Second, viewing this feature from a more positive stance, it has clearly seemed better to researchers to extend their work to a wider range of areas in order to map out the boundaries of the field rather than to concentrate further on those topics which happen to have been studied in the past. However, these extensions have tended to concentrate upon increasing the number of independent variables studied rather than on the dependent variables of MCS design and use, with only a few exceptions. This is connected with the almost complete absence of replication studies, perhaps accentuated because journals may have been unwilling to publish them. If such studies were to find null results it is less likely that they would be seen in print, although journal editors tend to dispute this interpretation despite the empirical evidence. Third, limited attention has been paid to the characterisation of the management control system itself. The initial focus was often on budgetary control, reflecting its widespread use in the 1980s, but has been extended to examine a wider range of performance measures and control techniques, but on only a sporadic basis. Finally, the predominant research method has been the use of survey questionnaires (often at arm's length) with quite limited use made of combining this work with more interpretative or critical qualitative methods. This seems to have been excessively limiting at what is still an early and exploratory stage of this field.

\footnotetext{
${ }^{7}$ The majority of the quantitative empirical studies involved data collection by mail questionnaire across a single or a number of different organizations.
} 


\subsection{Independent variables}

More and more variables continue to be examined. Major independent variables can be grouped into external variables and internal variables ${ }^{8}$. The most commonly examined external variables include technology, market competition or hostility, environmental uncertainty and national culture. The major internal variables are organizational size, structure, strategy, compensation systems, information systems, psychological variables (e.g. tolerance for ambiguity), employees' participation in the control systems, market position, product life-cycle stage, and systems change.

In the early stage of contingency research, many studies examined the relationship of just one independent variable with one dependent variable. However, Fisher(1995) argued that it is essential to understand the interactions between multiple contingent and control factors in determining the effectiveness of control system design. In other words, the understanding of the interrelationship between multiple contingent independent variables may lead to a better framework for dependent variables determinant analysis. He also classified contingency studies on management control by the level of analysis complexity. The work on the contingency theory of management accounting can be classified into 3 levels of analysis on this basis. At the first level of analysis, one contingent independent variable is correlated with one dependent variable. At the second level of analysis, the joint effect of multiple contingent variables on one dependent variable is examined. Some of these variables may be moderating or mediating variables rather than independent variables.. The third level of analysis examines the effect of the fit of multiple independent variables on several dependent variables, although this has been relatively rare. There is a trend in this stream of research for more variables to be examined in any one study with increasing attention being paid to their interrelationships.

\subsection{Dependent variables}

The most widely examined dependent variables are performance, performance measures, budgeting behaviour, management control system design and its use, effectiveness, job satisfaction, change in practices, and product innovation. Performance, effectiveness and design of systems are the major dependent

\footnotetext{
${ }^{8}$ The view of the author(s) has been accepted in this regard, although there is a debate as to whether an internal variable which can be affected by the firm itself should be treated as a contingent variable or as a dependent variable, most notably concerning organizational structure and strategy.
} 
variables used with financial performance being the most commonly used outcome variable. One of the major reasons is that financial performance is a widely used measure in most organizations. Moreover, most variable compensation systems use a measure of financial performance as the indicator for incentive payments. However, the over-reliance of performance measure on financial performance may produce biased results. The study by Coates et al. (1992) indicates that different countries have different preferences for performance measurement systems which may result from varying emphases on financial stability. Specifically, the employment of non-financial performance measures was more prevalent in U.S. companies at that time. Many of the performance measurements which are highly valued and of significant impact, are non-financial measurement such as production process measures, defect rates, cycle time and customer service measures; or qualitative measurement, such as customers' perception, attitude of employees towards jobs, and product innovation. (Otley, 1999). Despite of the importance of non-financial and qualitative performance measurement, these variables have been relatively neglected in the studies reviewed here.

These mainly quantitative studies form the core of what has become known as the contingency approach and have formed the foundation of our knowledge about the major variables thought to affect the design and use of MCSs. They have also increasingly paid attention to the interactions between both the independent and the dependent variables, a topic further discussed in sections 5.5 and 5.6. However, it is perhaps unfortunate that the term 'contingency' has now become associated only with the methods typically employed in this strand of research when a wider range of research approaches are likely to give additional insights. Whilst acknowledging the knowledge that has been gained from these studies it seems likely that further progress is most likely to be obtained from deploying a much wider range of research approaches, given the complex nature of the phenomena being studied.

Qualitative studies have emerged more recently and are more difficult to categorize, ranging from detailed analyses of very specific and small scale operations, through to overviews of whole areas, often with a theoretical component. The empirical techniques involved were usually interviews as the main evidence gathering technique, although this was sometimes supplemented by documentary evidence and questionnaire responses from managers. These will not be reviewed separately in detail as they are few in number and difficult to compare and aggregate, although they have yielded some significant insights into MCS development, modification and 
use. $^{9}$ The work reviewed here does not do full justice to the number of contributions already made to management control research using qualitative methods, as many of the studies would not describe themselves as being within the 'contingency' tradition. It may well be that the use of this label is now becoming obsolete as studies focus on how MCSs occur in the forms that are observed and the effects that different configurations have on managerial and organizational behaviour.

Rather than trying to impose what would likely be an artificial order of the range of work being considered, this review will take a topic-based approach and examine the areas where significant amounts of work have been conducted, with a view to drawing out some lessons which can be learned for the conduct of future research. This is inevitably selective, but has been done in the hope that an overview of a few areas will prove more insightful than a more comprehensive yet inevitably more superficial review of a large number of widely varied studies. This section will also include a discussion of some methodological issues which have been discussed. It will conclude by suggesting issues that future work might usefully consider. A full bibliography of all the articles considered is attached in Appendix $A$, with the reference list at the end of this article containing only those references not included there.

\section{Review of some selected bodies of work}

As has been observed above, the empirical work which has been undertaken is difficult to categorize neatly, with little cumulative progress having been made, due to successive authors designing their studies with only limited connections to previous work. It is also worth noting that the context within which many of the earlier studies were conducted has changed substantially since that time, and that their results may not be applicable to today's organizations. However, a number of major themes have emerged which will now be discussed in more detail.

\subsection{Reliance on accounting performance measures (RAPM)}

Early work on contingency theory tended to be based on prior findings from organizational behaviour, but one important stream developed from conflicting

\footnotetext{
${ }^{9}$ But see section 5.6 for further discussion.
} 
empirical observations that required explanation. This started with the work of Hopwood (1972, 1974a) who examined the effect of senior managers giving a high priority to accounting performance measures in evaluating the performance of their subordinates, a style later characterised as RAPM. The main result was that where accounting performance measures (in particular, meeting the budget for the unit) were given higher significance than other criteria, such as long-run effectiveness, then a variety of undesirable consequences followed. A subsequent study by Otley (1978) deliberately chose a situation where he believed this result would not hold (i.e. where operating units where largely independent of each other, in contrast to Hopwood's highly interdependent units), and found the conflicting results he predicted. He argued that this was therefore a contingent result dependent upon the contingency of sub-unit interdependence. However, this proved to be a contentious conclusion as there were several other differences between the two studies (e.g. US versus UK organization; private versus public sector; cost centres versus profit centres; size of organizational unit etc.) and subsequent work sought to explicate some of these possible differences and what their consequences might be.

The work which followed, despite being described as "the only organized critical mass of work in management accounting at present" (Brownell and Dunk (1991) (p.703)) had a major deficiency in that very different measures of the central concept (RAPM) were used in different studies. These difference were outlined and reviewed in Otley and Fakiolis (2000) which concluded that many of the studies were not comparable with each other due to these differences in measurement. Significantly, both Hopwood's and Otley's studies made significant use of interviews in developing their questionnaire-based measures and in interpreting their results, whereas later studies tended to use arm's length general purpose questionnaires, sometimes used across a variety of different organizations. Using the over-arching term of RAPM was itself misleading as it covered the use of several different measures which each focussed on different aspects of the underlying phenomena. Further, the appropriateness of the questionnaire items to the specific organizations being studied is unclear as validation through fieldwork was usually absent.

In addition, the world had moved on from the situation that existed in the early 1970s (see Otley (1994) for an analysis at that date). Budgetary control had reduced in significance as a performance measure, with non-financial measures increasing in importance. Organizational structures had become flatter and inter-organizational relationships had increased in importance as out-sourcing had become more prevalent. These trends have continued to the present day and it seems unlikely that 
results which were found in the past can be relied upon to hold in the present day. At the very least, this needs to be investigated rather than reliance being placed on work conducted long ago. The one major attempt to construct a broader framework was Simons (1995) work on Levers of Control which was based on a large number of case studies conducted in US companies, generally involving data from CEOs and other senior managers. He focussed on a much wider set of controls than most previous studies (categorized into diagnostic, interactive, beliefs and boundary controls) although his formulation has proved to be somewhat problematic as identified and then improved by Tessier and Otley (2012). But subsequent research focussed almost entirely on his distinction between diagnostic and interactive uses of controls, and the ambiguity in the definition of interactive use has also led to the term being used to cover a variety of different measures. Indeed, Bisbe et al.'s (2007) review of this concept identified five different dimensions of the concept which had been aggregated in a variety of ways. The consequence is that, when the literature refers to the use of interactive controls, very different concepts may be found within this single label because of the different measurement instruments being used.

However, the underlying idea behind the early studies does appear to have a continuing significance in a world which is becoming increasingly dominated by performance targets of all types. That is, managers who place reliance on motivating appropriate subordinate behaviour by setting quantitative performance targets and emphasizing these above all else, should not be surprised if such targets are attained by a variety of (often unobserved) behaviours that are often dysfunctional to the achievement of overall organizational objectives. There is overwhelming empirical and anecdotal evidence to this effect from both the private sector (e.g. call centre operatives cutting off calls before they reach the target time for dealing with enquires) and the public sector (e.g. school teachers concentrating on those pupils whose results will most affect the performance target; hospital ambulances being made to wait outside $A \& E$ departments so as not to start the time clock for target treatment times etc. etc.). Even university academics have been affected by the Research Assessment Exercise in the UK where administrators have converted the subjective rules involving peer judgement to quantitative targets of achieving a given number of articles in journals believed to have a high quality rating.

It is therefore a pity that this stream of research seems to have dried up because of the measurement difficulties associated with a particular set of measures designed to measure RAPM. The underlying concept still seems sound and very relevant to modern organizations, particularly if modified to include non-financial as well as 
financial performance measures and targets. In particular, RAPM focussed on the ways in which line managers actually used the accounting (and other) information supplied to them in the process of holding their subordinates accountable for their performance. This is still a key area that is deserving of continuing attention.

\subsection{Environmental uncertainty and hostility}

Of all the variables used in the original studies of the contingency theory of organizational structure, the one that has gained by far the widest attention in the area of management accounting is that of environmental uncertainty. This seems to be for several reasons. First, it produced some of the strongest results in early studies, in a similar way to the ground breaking work of Burns and Stalker (1961) in the organizational literature. If an organization or unit is faced by high levels of uncertainty it requires flexible and adaptable systems to manage activities when unexpected events occur. Second, it can be argued that environmental uncertainty has increased over the years, in part due to the emergence of the global economy and more extensive competition. But it is also caused by organizations ceasing to attempt to control all aspects of the value chain within one overall (holding) organization and the relative demise of the divisionalised organization. This exposes the smaller and more focussed organizational units to more uncertainty that, in the past, may well have been buffered by the overarching organization. Third, there is also the issue of measurement. Here the most commonly used variable is a measure of perceived environmental uncertainty which can easily be incorporated into interviews or questionnaires administered to individual managers. Although this may be seen as using a very subjective measure, it can also be argued that this is the most relevant aspect of uncertainty - it is the uncertainty perceived by individuals that will most directly affect their behaviour. However, it is only indirectly connected with more objective measures of risk and uncertainty and the factors which cause some individuals to perceive greater uncertainty than others are not specified ${ }^{10}$.

Associated with, but distinct from uncertainty are other aspects of the environment, including hostility, particularly that related to intense competition. Although hostility may produce a significant degree of uncertainty, the findings of most studies indicate that the two features have diametrically opposed impacts on MCS design and use. Hostility has been shown to be associated with a greater reliance on accounting

\footnotetext{
${ }^{10}$ A useful review of the impact of uncertainty on performance measurement and compensation systems can be found in Abernethy and Mundy (2014).
} 
controls (especially budgets) whereas uncertainty is associated with a more flexible style of control that is open and externally focussed. As Chenhall (2007) has pointed out, it is an open question how the tension between these two factors should be managed in an MCS given they may often occur simultaneously. This of indicative of a common problem with contingency studies in determining how multiple contingencies having conflicting recommendations should be combined. It also draws attention to the common issue of distinguishing between the existence of formal controls and the ways in which they are used by managers.

\subsection{Strategy}

Strategy has been hypothesized to affect control systems design in a number of straightforward ways, depending on which categorization of strategy is used. Following Miles and Snow (1978) who described four organizational types (defenders, prospectors, analysers and reactors), it has been suggested that defenders undertake little product innovation, whereas prospectors are continually searching for new market opportunities, either for existing or new products. The former type therefore concentrate on finance, production and engineering, compared with an emphasis on marketing and $R \& D$ in the latter. Analysers are thought to combine the strongest characteristics of both defenders and prospectors, whilst reactors are seen as an unsuccessful type and are rarely examined.

In a similar vein, Porter (1980) distinguished three generic strategies - cost leadership, differentiation and focus. The competitive advantage of cost leaders is focussed on the economics of scale, the operation of efficient procurement and efficient production technology. By contrast, a differentiation strategy seeks to focus on providing products that are highly valued by customers who are thus prepared to pay premium prices. Finally, a focus strategy dedicates itself to catering for a segment of the market that is poorly served by competitors. Here again the control system focus will be on either cost control or on product qualities based on customer satisfaction.

Finally, Gupta and Govindarajan (1984) developed a life cycle approach based on the sequence of strategic missions from build, hold, harvest and divest. In the early stages the focus is on building a market share and strategic position, with lesser emphasis on short-term earnings or cash flow. As the business moves to a harvest strategy a firm ceases to invest except where strictly necessary and seeks to achieve short-term profit and cash flow rather than increasing market share. A hold strategy is intermediate to these two, where a firm seeks to protect market share and strategic 
position whilst obtaining reasonable returns. Finally, the divest strategy occurs when a business decides to exit from a specific area of activity. Each strategy again tends to be associated with a specific group of controls.

Although these different characterisations of strategy share some similar control system attributes, there does not seem to have been any coherent comparison between them. Rather, the empirical studies on the impact of strategy on MCS design and use tend to select one typology to work with, and to follow the implications of this for MCS characteristics, although again focussing on different MCS features in different studies. However, the stream of work by Simons ${ }^{11}$ focuses on the choice companies make between the diagnostic and interactive use of controls work to support their strategic intent. Unlike previous empirical studies, in Simons' work the content of the strategy is not seen as critical to understanding the nature of the interaction between controls and strategy, using his typology of diagnostic and interactive use, beliefs systems and boundary systems.

A good review of the earlier work on strategy and control can be found in LangfieldSmith (1997) although the topic seems to have waned somewhat in interest since that time and no further overview articles were found. More usefully perhaps, there have been some more detailed, qualitative studies that have tried to capture the details of actual strategies adopted and the ways in which these have influenced the use of control systems. One of these by Adler \& Chen (2011) indicated the existence of a confrontation strategy (as distinct from cost leadership or differentiation) which was associated with collaborative organizational cultures, lean organizational structures and practices, and training and development programmes that focussed on developing empowered, multi-skilled teams of self-governing and coordinating employees.

Thus the contingency work on the relationship between strategy and MCS design and use is fragmented in several ways. First, there is a reliance on simple generic strategy characterisations that may fail to capture the complexity of real organizational strategies. In addition, it is not always clear whether what is being measured is an espoused or a realised strategy, or even whether an overall organizational strategy is being assumed to apply in an organizational sub-unit that may be responding to different local circumstances. Second, the dimensions of the

\footnotetext{
${ }^{11}$ These are. summarized in Simons (1995). Interestingly his individual studies were not identified in the literature search, despite being reported in journal articles, as they make no specific reference to ideas of contingency.
} 
control systems examined are varied with no agreed structure or content, leading to piecemeal results, although Simons' work represents a distinct approach grounded in case-based research. However, it has not achieved any great popularity in contingency work, except for his distinction between diagnostic and interactive uses, perhaps partly because it does not connect easily with any other established framework. Although serious attempts have been made to achieve a greater degree of coherence in framework specification by Malmi \& Brown (2008) and by Ferreira \& Otley (2009) there is much still to be done to develop a useful general framework that will allow the results of future studies to be validly compared.

One recent piece of work by Klassen (2014) has suggested that there may be an underlying variable that is logically prior to strategy, namely value logic. Essentially, a value logic is the basic business model adopted by an organization and has been categorized into three types: value chain, value network and value shop (Stabell and Fjelstad, 1998). A value chain is the traditional structure occupying one position in a chain of activities stretching from raw material through to final products or services (e.g. a manufacturing company); a value network relies on the connections that an organization has with other organizations to provide an overall service to clients (e.g. a bank); a value shop is an organization that contains within it a range of specialised resources that can be mobilised to provide a personalised bespoke service for clients (e.g. a professional services firm). Klassen has shown that the differences between the control systems of value chains and value shops are quite distinct, and value logic may thus be more fundamental to MCS design than strategic positioning. His results are less clear for value networks (which are generally in an intermediate position) perhaps because these take several forms and a more precise definition of their characteristics may need to be developed.

The contingency work on the impact of strategy on MCS is thus fragmented and it is difficult to find cumulative contributions. This is partly due to arbitrary classifications of strategy, which although necessary for survey work, may categorize actual strategies too simplistically. Here the pursuit of work that focuses on the underlying variable of value logic may provide a route to further progress at the more general level, with more interpretative studies, which will inevitably focus on small samples of organizations, providing more specific detail. The lack of cumulative progress is also due to a lack of consensus on the characterisation of the MCS itself, which will be dealt with in section 6 . 


\subsection{Culture}

There has been a significant amount of work which examines the effect of culture (usually national culture) on the design and operation of control systems with some 25 articles in the bibliography being on this topic. Much of the work has been conducted by US-based authors studying Chinese (or Taiwanese) culture and many articles rely upon Hofstede's early work on the topic which was reported most fully in 1980. It is relevant to note that the database for his work consisted of IBM employees working in many different locations, so may give a biased representation of employees in other organizations despite its impressive national coverage. Hofstede (1980) initially identified four major dimensions on which national cultures could be distinguished: power distance, individualism, masculinity and uncertainty avoidance. He later added short-term vs. long-term emphasis, and Minkov (2010) added pragmatism and indulgence based on World Values Survey data. Essentially, these studies depended upon forms of statistical analysis such as factor analysis to identify underlying clusters of variables which were then given the above labels.

What is notable about the MCS work is that differences in national cultures are often merely assumed to be different in studies, rather than being measured by them, and they are also assumed to accord with the results of Hofstede's early studies, despite the age of his work. In a few cases an instrument based on Hofstede's work is used to construct a measure of some cultural values for a specific sample. The outcome is that studies are rarely comparable even on how culture is defined or assumed to be, let alone with its effects on control systems. Here the extant work studies different aspects of control systems, with many finding that apparently intuitive hypotheses are not substantiated. So it proves almost impossible to generalise about even the major effects of (national) culture on MCS design and use.

This is probably mainly due to two effects. First, national culture, even if captured by the measurement instruments used, is an average within which there is almost certainly a wide range of variation between individuals and groups within a country. The employees of a particular company may well differ significantly from the stereotypical behaviour that an overall average provides. Second, it is likely that organizational culture will also have a significant influence on attitudes and behaviour within an organization. Unless some attempt is made to measure the cultural values and assumptions of the particular employees in question, then it is likely that any results will contain significant amounts of noise. Again, there is likely to be considerable variation between individuals and, in addition, in these days of global 
employment, many employees in a single location may well have been brought up in different national cultures. But organizational culture can also be managed to an important extent and significant examples exist of training regimes that have changed the behaviours of key employees in certain organizations (e.g. airline pilots in a Korean airline who previously tended to have such a high level of hierarchical respect that they failed to question the decisions of a senior pilot even when these were thought to be clearly inappropriate, and in some cases led to major accidents). Organizational culture is probably best seen as a mediating variable through which national culture acts in influencing behaviour in organizations.

These comments should not diminish the importance of studying organizational culture and its impact on employee behaviour as organizational culture is an important control mechanism (Ouchi, 1979). According to Fisher (1995) organizational culture implies a set of social norms, values and beliefs that are shared by the members of the organization and influence their actions. He argues that a strong internal culture can decrease the need for other control mechanisms, and may thus affect the overall design of an MCS. This is therefore an important area for continued work, despite the difficulties that will need to be overcome to obtain results of any generality.

\subsection{Effectiveness}

The idea of a contingency fit requires some measure of effectiveness to act as a criterion variable. That is, a good contingent fit can be defined as achieving higher effectiveness than a poor fit. But how effectiveness is defined and measured varies considerably across studies. Initially some studies merely assumed that existence was itself a measure of effectiveness, generally on the (often unstated) grounds that in the long-run equilibrium considerations would lead to observed occurrences stemming from a good fit, whereas cases of a poor fit would have gone out of existence. Not only is this implausible in modern conditions, but empirical studies which analyse a large dataset require some variable to act as a criterion, so each such study requires a measure of effectiveness. These vary depending on the topic of the study; for example product innovation has been used in studies where the focus is on MCS design and use that support innovation. But the most commonly used measure of effectiveness, by far, has been financial performance, usually profit or return on investment. 
There are two major problems with using profitability as a criterion variable to determine contingency fit. Firstly, profitability is affected by a huge range of factors other than MCS design or use. Thus a great deal of random noise can be expected. Additionally, the unit whose profitability is used should ideally be different for each of the managers included in the study (or issues about the appropriate unit of analysis will be raised). Secondly, financial performance has been argued to be a contingent variable in its own right. For example, an organization facing poor financial performance is highly likely to pay more attention to financial control techniques such as budgeting. If this is the case, then the apparently perverse result that the extensive use of budgeting is positively associated with poorer financial performance can be expected. Certainly, it is not possible to use financial performance as a criterion variable if it is wished to study its role as a contingent variable, which is perhaps why few studies have undertaken such an investigation. Nevertheless, it is possible to avoid this issue by either using a different measure of organizational effectiveness, or by using a managerial estimate of control systems effectiveness, despite the issues raised by using data from the same manager to report both on the nature of the system and on its effectiveness (particularly if that person has been involved in the design of the system).

There are also wider issues in determining how 'fit' can be assessed. These are well set out in Gerdin and Greve (2004) who identify a number of different types of fit (Cartesian vs. configuration; congruence vs. contingency; and mediating vs. moderating) each of which is appropriate to different types of hypothesis. They also consider whether it is the form of a relationship that is being hypothesised, or its strength. They then analyse a number of major studies which use strategy as a contingent variable and conclude that there is widespread confusion in the way 'fit' has been conceptualised in different studies (and sometimes within the same study). This was followed by a later article (Gerdin and Greve, 2008) which attempts to set out the appropriate statistical to assess whether a given type of fit has been achieved or not.

Where several contingent variables are used there are difficulties in analysing and understanding the results obtained in studies. A popular early method was to use an interaction effect in a regression equation, where the interaction term is the multiplication of the two independent variables involved. This is not problematic (provided the regression model is appropriate to the hypothesis being tested (see above)) but becomes more complicated when the number of independent variables increases. Three variables seems to have been the practical limit, but even here the 
interpretation of a three-way interaction is complicated and a clear explanation often requires it to be broken down into sub-parts, usually by dichotomising one variable into two levels (e.g. high and low with respect to its mean) and examining each subsample so formed separately, despite the information loss in such a process. ${ }^{12}$ This process also draws attention to the common practice, often also implicit in the statistical techniques used, of referring to levels of a variable being high or low by reference only to other values in the sample rather than to some external benchmark, making comparability between studies difficult.

There has also been extensive debate on the role of appropriate statistical methods when testing for the existence of mediating or moderating variables in contingent relationships. Hartmann and Moers (2003) argued that there were many cases in the literature where the theoretical reasoning led to the prediction of one of these hypothesized relationships being true, but that the statistical test used actually tested the other hypothesis. This provoked a debate on the topic which is well summarized in Burkert et al (2014) which outlines several different forms of fit (some of which had not previously been discussed). They assess the best statistical techniques that can be used in various circumstances and thus provide a useful guide for researchers developing large-scale empirical studies in this area. However, many of these techniques are still data hungry and may not prove feasible in many contexts, although statistical techniques such as structural equation modelling and path analysis can require less data to give statistically significant results.

There are thus practical limitations to understanding the complex interactions that may exist between more than a very few contingent variables at a time. It is unlikely that there could ever be a time when we would be able to predict the best MCS in a situation where there were more than a small number of important contingent variables, particularly where different variables pointed in conflicting directions. However, this narrow definition of what comprises a 'contingency study' is unnecessarily constraining, as pointed out by Chapman (1997), although he focusses specifically on accounting rather than MCSs more generally. In an important sense, all research on this topic can be seen as contingent, as we seek to understand the appropriate matching between the use of an accounting technique and the circumstances in which it is used, whatever types of research methods are used. Chapman also points out a confusion in the literature between complexity and uncertainty, with some scales purporting to measure uncertainty actually focussing

\footnotetext{
${ }^{12}$ This is an important area where more modern statistical techniques are proving to be very helpful in isolating the effects of a larger number of independent variables.
} 
on complexity. He argues for a dialogue between traditional, quantitative research approaches increasingly adopted in traditional contingency studies (even seen as defining them) and more qualitative, interpretative field studies aimed at gaining insight into the complicated processes by which accounting is mobilised and used within organizations. Although more of the latter type of studies have occurred in the period after his article was published, the movement towards the study of MCS and performance management systems (rather than just accounting systems) has also taken place, which has made the studies necessarily even more complex, and his plea for more field-based work is still very relevant. Given the dominance of non-US journals in reporting research in this field, it is perhaps surprising that qualitative work has been so relatively slow in developing, although there is evidence that this is beginning to change.

\subsection{MCS: Systems or packages?}

There has been recent discussion as to whether a set of control devices used by an organization are better regarded as a system or a package, although the distinction between these terms is not always made clear. The concept goes back to the use of the term 'package' by Otley (1980) where he uses it to refer to the separate parts of an overall management control system, but without any definition. ${ }^{13}$ The fullest discussion of the topic has been given by Malmi and Brown (2008) in their introduction to a Special Issue of MAR. Here they state that there are several reasons for considering an MCS as a package, First, the components of an MCS do not operate in isolation and the effect of any one needs to consider the context of the other components being used at the same time. Second, it seems necessary to consider an overall package of controls if the use and impact of a new MCS element is related to the functioning of the existing MCS package. Third, only some MCS elements are accounting-based and consideration needs to be given as to how these relate to broader controls (such as administrative or cultural controls) and whether or how these complement or substitute for each other in different contexts. They conclude by stating that "by taking a broader package approach to the study of MCS, researchers will be able to develop better theory of the real impact of innovations such as the BSC, and how to design MCS packages". (p. 288)

\footnotetext{
${ }^{13}$ My recollection is that I felt unhappy with using the term 'system' because it seemed to imply a designed system of well-coordinated parts, and many overall MCSs did not seem to possess this property. I used the term 'package' to imply a set of pieces that were put together without ensuring that they were fully coordinated.
} 
Included in the same Special Issue is also an article by Sandelin (2008) which compares the development of control systems in a single organization at two different points in time. This argues that, although the external context is very similar in the two 'cases' the control systems observed are very different. This is used, following Geredin (2005), to support an argument for 'equifinality', namely the fact that two different systems may actually produce equivalent (or equally good) outcomes, and that there is no 'one best way' even if this is considered in contingent terms.

Malmi and Brown seem however to go only part way down the path they have identified, as they seem to pay limited attention to the phenomena often observed in practice that the elements of an overall control system may not be well-integrated or coordinated. The fuller idea of a package should perhaps incorporate this idea, which is sometimes referred to as 'loose coupling', although it is often not clear whether this is regarded as intentionally designed or accidently achieved! This idea was developed by Orton and Weick (1990) and Malmi and Brown suggest that it might be fruitful to follow a similar approach in characterising the linkages between the elements in an MCS package.

The main contribution of the Malmi and Brown article seems rather to be the typology they give of the various categories of control that form an overall package. These are seen as falling into five different categories, most centrally Planning and Cybernetic Controls (essential ex post and ex ante control), together with Reward and Compensation. These are supplemented by Administrative Controls (which include both governance and organizational structure) and all are included within a wider set of Cultural Controls. This provides a valuable supplement to the twelve questions suggested by Ferreira and Otley (2009) in their proposed framework for the study of overall control systems, although they make little reference to the idea of packages except in their question about coordination between controls.

A limited conceptualization of an MCS and its components permeates the literature. Most articles select just one component of an overall system for study (such as budgeting, use of a BSC, or compensation system) and proceed without any reference to the other components that surround it. It is rare for an attempt to be made to capture the totality of an overall system, although some of the users of the Ferreira and Otley (2009) framework have tried to move in this direction. This is gratifying to me as the framework was put forward in order to make it more feasible for researchers to attempt such a task. Some use has also begun to take place of the Malmi and Brown (2008) categorization, but these studies comprise just a small 
part of extant work. Grabner and Moers (2013) have also tackled the problem of more precisely defining the idea of internal consistency which has been used to define an optimal (perhaps closely coupled) MCS package. However, their work is primarily analytic and is mainly concerned with the conceptualisation of 'internal consistency' based on a number of assumptions, before addressing some implications for empirical studies. There is therefore scope for this issue to be examined from an empirical perspective to complement their analytic approach. One example of such work is Gong \& Ferreira (2014) which seeks to examine whether consistency in management control systems design choices affects firm performance, with their results showing a positive relationship.

The importance of overall context had also been emphasized by Nixon and Burns (2005) in their introduction to an earlier Special Issue of MAR. They drew particular attention to the idea that change had itself changed by becoming much more rapid. The idea that periods of change are punctuated by periods of equilibrium has become outdated. They also drew attention to the continued existence of two gaps: first, that between extant management control literatures and management practice, and second, between the management control literature and other literatures. They argue that these issues "increase the persuasiveness of longstanding criticisms of the theoretical foundations of management control" (p.262). This view is strongly reflected in one article in that Special Issue by Collier (2005) which provides an interesting perspective on several control issues, namely the changes that occur in management control over an organizational life cycle, the degree of consistency among different controls, and the interaction between formal, systems-based controls and informal controls. In addition, he argues that both the frameworks of Ferreira and Otley (2009) and Simons (1995) pay too little attention to beliefs controls, and concludes that modern organizations will have to develop controls which allow them both to compete today and to prepare for tomorrow.

Finally, Mundy (2015) has developed the idea of loose coupling in MCSs following earlier work by Demartini (2011). Although developed in both organization theory and economics, this idea has yet to be fully applied to MCSs. Mundy takes the view that MCSs within many organizations constitute a package of distinct management control elements that have been separately designed and implemented without an overall intention or coordination, but where each element aims to facilitate the attainment of different aspects of organizational goals. She applies this to examine the patterns of interaction observed within a MCS package in a single organization, and interprets these as an exemplar of loose coupling. Of particular interest is her 
documentation of management 'workarounds', that is, informal practices that enable the overall package of control to function better than observation of just the formal systems might imply. She characterises the coupled nature of interrelations within an MCS package using four dimensions: mode, directness, directionality, and frequency, and demonstrates the actual functionality of a specific package of controls despite its parts having been implemented at different times, by different individuals and for different purposes.

These studies indicate an emerging view that overall MCSs are influenced by their content and trajectory of development as well as by traditional contingent factors. As external change occurs, control systems are adapted, often by the addition of additional features or systems (and perhaps less by the removal of practices which have become outdated, as these tend to fall into disuse rather than being removed). Rather than moving from one equilibrium to another, such systems resemble packages which are constantly being modified and developed with the ever-present danger that they become internally inconsistent and incoherent. Although this can be (and perhaps should be) tackled as part of their development process, in practice MCS packages will inevitably contain inconsistent and contradictory elements. It appears that informal processes are likely to play an increasingly important role in helping preserve their continuing functionality.

\section{A characterisation of MCSs and their context}

The above critiques have concentrated on the specification of different contingent (independent) variables that have been frequently used in the literature. It is surprising that a similar amount of attention has not been devoted to the dependent variable of the MCS and aspects of its design and use. By contrast, this has generally been treated in a fragmentary manner with just one or two aspects selected by each reported study, with very little work attempting to gain a holistic view of the overall systems in use by an organization. Admittedly, this is a significant task to attempt, particularly with the lack of frameworks to assist in categorizing such MCS components. For example, Ferreira \& Otley (2009)) focus primarily on the purposes served by the components of such systems, whereas Malmi \& Brown (2008) attempt a basic classification of tools and techniques, but again concentrate on their use (e.g. planning, control etc.). It seems likely that more useful progress will now be gained by a greater focus on the MCS itself, how its elements may most usefully be conceptualised, and how they are inter-related. This requires a richer conception of 
the reality of the actual control systems extant in organizations, and an attempt to characterise this is set out below.

Organizations exist in an environment of considerable uncertainty ${ }^{14}$. Business organizations, in particular, working in a competitive environment can never totally predict the actions of their competitors or what technological innovation may occur and on what time scale. They also depend upon other organizations as either supplier, customers, service providers or network partners, and these relationships are subject to ongoing change. The overall economic environment is now global and increasingly unpredictable as no sector is immune to changes happening far away. Even the public sector is subject to some of these features and also by the vagaries of public policy, changes in which can sometimes be quite sudden and unpredictable. In addition, the internal organizational environment is also subject to considerable uncertainties about how employees will communicate, coordinate and generally behave in ways conducive to efficient operations. ${ }^{15}$

Of course, different types and amounts of uncertainty exist in different environments, and these differences have been the focus of one major contingent variable. But it needs to be recognized that substantial uncertainty is present in all organizations and that they need to cope with this, as argued in Otley(2014). Thus MCSs need to be able to operate in such an uncertain environment and may need to be adapted to cope with this ever more common circumstance. For example, the Beyond Budgeting movement has claimed that in this 'new' environment budgeting is fundamentally past its sell-by date and needs to be replaced with a better system (Hope and Fraser, 2003), although it now seems to have modified its claims of being an alternative system to the more modest suggestion that it comprises a set of useful tools (see Hansen et al., 2003). Nevertheless the majority of organizations of any size still have budgetary systems, although these may have been adapted in a variety of ways (e.g. more frequent updating; shorter time-spans; rolling budget systems etc.; different patterns of budget use for different purposes etc.). What is evident is that budgetary control has been displaced from the central place it occupied forty years ago and supplemented by other systems, most notably Balanced Scorecard-type systems containing a variety of non-financial measures of

\footnotetext{
${ }^{14}$ See Otley and Soin (2014) for a set of essays on how uncertainty affects the design and operation of MCSs.

${ }^{15}$ I well remember as a PhD student being 'reprimanded' by my teacher of organizational behaviour for concentrating excessively on dysfunctional behaviour. Isn't what is really surprising, he suggested, is that organizations actually work as well as they do, and shouldn't we concentrate on trying to understand how they achieve such remarkable consistency and regularity?
} 
performance. In addition, these performance measurement systems are often complemented by performance-related pay systems which rely on further (and sometimes different) performance measures, and which are usually different at successive hierarchical levels.

A central feature of the elements (sub-systems) of an overall MCS is that they comprise of largely independent systems in their own right. For example, we still have budgetary control systems (although the ways in which these are used may have changed markedly), but also non-financial performance measures, perhaps integrated into a dashboard or scorecard, risk management systems, incentive payment systems, corporate governance systems and strategic control systems as well as many others. These have generally been developed by different (groups of) people at different times, often with a particular and limited purpose in mind at the time of their implementation. In addition, they may impinge differently within each organizational function, and at different hierarchical levels. Thus it often seems to make more sense to think of an organizational control 'package' as the different elements are likely not to be perfectly coordinated with each other. For example, the performance measures driving a senior management bonus scheme may not be those specified in the top-level BSC ( a real example!).

This process is dynamic. Changes may be made from time to time, often with the purpose of aligning disparate systems with each other. These will often be successful in their own right, although there are often significant lags in alignment being achieved (payment systems being particularly 'sticky' in this respect as they often require renegotiation with groups of employees; and computer systems are invariably slow to get updated). However, other new systems may also be introduced that have their own differences from the extant package, and the speed of improvement often lags the rate of introduction of new elements.

The ways in which employees use the elements available to them often changes over time, sometimes quite rapidly. When Mundy (2015) documented the 'workarounds' that were adopted in the organization she observed, these could be generally described as functional in that they allowed ill-coordinated systems to be made workable by these informal changes. Additionally, in multi-national organizations another layer of complexity often arises in that systems which operate ell in one national environment may work very differently in another national culture. Mergers and acquisitions also often display instances of systems change which 
proves ineffective because of the differing organizational cultures of the combining organizations.

Finally, more organizations have become part of a value chain that covers several independent organizations, which have no common ownership or superior authority, yet still need to coordinate their operations. Many of these seem to have one organization in a dominant position, either because it is significantly larger than the others, or it has a monopoly over the route to the ultimate consumer, and here its systems will tend to be imposed. For example, most cases of open book accounting seem to display this characteristic. But others are comprised of more equal partners who need to devise arrangements to achieve better coordination and control, and are often in a continuing process to adapt their arrangements.

It has become usual for such partly co-ordinated combinations of elements into an overall system to be labelled as 'loosely- coupled' although this term seems to cover both intentional design and accidental outcomes. It seems probable that most of the looseness of coupling in MCSs is accidental rather than intentional, although this is an empirical question which would be interesting to investigate. However, the overall context and design of an overall MCS requires to recognize the type of environment in which it operates, both in terms of specific factors and general overall trends. In particular, researchers need to view the systems they are studying from the above perspective, and to adopt research designs and methods that can cope with this complexity. Although 'snapshot' pictures of the type generated by arm's length quantitative studies have their place and can cover a range of organizations, their design needs to standardize and control for, as far as possible, the variables that they are not able to measure, so that the results are not contaminated by unknown random variation. More insight will probably be gained, especially in what are early days in studying complete control systems in their entirety, by field studies of a small number of organizations in some depth and preferably over time. We understand relatively little of the development of MCSs over time and the complex ways in which the technical components of these complex systems, their interactions, and the ways in which managers use them, are important aspects for study.

Such studies may well not follow a formal, contingent approach, but they rest on the important information that previous studies have provided. However, it is important to recognize that it is likely that these previous results are neither universal nor constant. That is, a specific study will have taken place in particular conditions, many of which have not been documented or even measured; even if valid in that situation, 
the passage of time may well have changed other relevant factors as well. So the result is perhaps usefully indicative of the types of system that can exist, but it is unlikely to have the predictive power to predict what will be found even in other apparently similar circumstances. The type of knowledge we have obtained is not that of a hard, scientific nature, where experiments can be conducted on phenomena which have constant properties at different times and in different places. It is knowledge about how processes and interactions between processes occur, so that we are in a position to understand the generalities of behaviour that occur in such systems, rather than being able to predict the outcomes in any set of specific circumstances without further investigation.

\section{Conclusion}

The work conducted under the banner of contingency theory has been one of the success stories of research in management accounting and control over the past forty years. It has given insights into how different configurations and uses of control systems have resulted in a variety of different consequences. However, it has also been tantalisingly inconclusive and has produced little cumulative knowledge. This is perhaps because it has (implicitly) set out to produce knowledge of a type which may not exist in the complex and changing world of organizational control. As Saulpic and Zarlowski (2014) point out, we need to recognise that in this field "research does not often lead to establishing what does or does not work in a specific organizational context" (p.215). We are unlikely ever to be able to produce knowledge of the type that is generated by the physical sciences as our subject matter does not have the stability and uniformity of physical matter, nor is it amenable to controlled experimentation.

In this context, one way forward can be found in the deployment of what has been termed Middle Range Thinking (MRT) by Richard Laughlin and well expounded in Broadbent and Laughlin (2014). They argue that "a research approach using MRT provides important insights into the nature and functioning of MCSs, particularly in conditions of uncertainty" (p.255). They view the social world not as rule governed but rather as interpretively constructed, which implies that it cannot usefully be characterised solely by tight theoretical descriptions. Yet this social interaction is also embedded in the context of existing yet dynamic social structures and institutions. This is not to suggest that researchers should go into the field free of theory (an impossibility in any case), but the theories that are being assumed should 
be made explicit and remain open to adaptation. Such an approach represents a middle ground between taking a firm initial theoretical position and the attempt to build interpretations uncontaminated by prior beliefs, as is sometimes suggested by the proponents of grounded theory. It suggests that such theories cannot be 'tested' in the ways that positivistic research approaches might demand, but still allows them to be open to change in the light of new interpretations. The underlying theories can be seen as a 'skeleton' that give researchers a language to discuss the empirical situation and which are given meaning by the empirical 'flesh'. As they summarise their position 'Just as the theoretical 'skeleton' need empirical 'flesh' to give it meaning, so the empirical flesh is given shape by the theoretical frame." (p.257)

The MRT approach therefore gives theory a different role than that taken by the positivist approaches used in the natural sciences. In the social sciences theories will be less all-encompassing and will possess a much more limited predictive ability, yet remain important for codifying the common understandings of researchers working in a particular field. Yet these understandings will inevitably be partial and subject to continual modification and change. As they conclude "MRT accepts that we can derive generic theories ... but that such theories will always be 'skeletal' in nature as the nature of understanding is uncertain and changing." (p.267). This implies that all theoretical structures in this field require empirical 'flesh' to provide an adequate explanation of observed behaviours. But whatever theoretical approach is adopted it needs to take seriously the inherent uncertainty in the world we are studying and the types of knowledge that it will be possible to discover.

In particular, a major deficiency of much prior work has been the lack of attention paid to the conceptualization of the overall MCS. Although many elements of an overall MCS have been studied, these have been seen in isolation from the context of the other elements which surround them. The idea of a 'package' of control systems has been in existence since at least 1980 but has only recently begun to be taken seriously. At the very least, researchers need to take pains to set out and report the context (both external and internal) in which their data has been gathered in order that the limitations to its generalisation can be made apparent. In addition, few studies have yet attempted to take an overview of the overall package of controls being deployed in an organization and to study the dynamics of how these develop and the outcomes that result. MCSs are deployed in an environment of considerable uncertainty where even responsible managers may have an incomplete understanding of how outcomes will result from their decisions. The limitations of 
knowledge and the types of theory that are possible need to be more explicitly acknowledged.

But this is a vitally important topic where researchers can develop insights which can both help to establish theoretical propositions and also have practical impact in the world of organizations. The work of Simons (1995) and the case studies on which it is based give one exemplar as to how this can be done. But the task has only just begun, and there are a multitude of opportunities open to researchers working in this area. I look forward to seeing the results of their endeavours in the pages of future issues of Management Accounting Research.

\section{Acknowlegments}

The author would like to acknowledge the help given by Yahui Dong and Ying Sun, two M.Sc. students at Lancaster University who helped compile the bibliography. Also to participants at the Management Accounting Research conference held at the LSE in April 2015, and to Professor Bob Scapens, Professor Michael Bromwich and an anonymous reviewer for their helpful comments.

\section{References}

(excluding those included in the bibliography)

Abernethy, M. and Mundy, J. 2014. Uncertainty as a Determinant of Performance Measurement and Compensations Systems: A Review of the Literature. Chapter 8 in Otley, D. \& Soin, K., Management Control and Uncertainty, Palgrave Macmillan, Basingstoke, UK. 114-133.

Adler, P.S. \& Chen, X. 2011. Combining creativity and control: Understanding individual motivation in large-scale collaborative creativity. Accounting, Organizations and Society, 36(2), 63-85.

Anderson, S. and Dekker, H. 2014. From Make-or-Buy to Coordinating Collaboration: Management Control in Strategic Alliances. Chapter 4 in Otley, D. \& Soin, K., Management Control and Uncertainty, Palgrave Macmillan, Basingstoke, UK. 47-68.

Anthony, R.N. 1965. Planning and Control Systems: Framework for Analysis. Division of Research, Harvard Business School, Boston MA.

Bisbe, J. and Otley, D. 2004. The Effects of the Interactive Use of Management Control Systems on Product Innovation. Accounting, Organizations and Society, 2(8), 709-737. 
Bisbe, J., Batista-Foguet, J., Chenhall, R. 2007. Defining management accounting constructs: A methodological note on the risks of conceptual misspecification. Accounting, Organizations and Society, 32(7-8), 789-820.

Broadbent, J. and Laughlin, R. 2014. Middle-Range Thinking and Management Control Systems. Chapter 16 in Otley, D. \& Soin, K., Management Control and Uncertainty, Palgrave Macmillan, Basingstoke, UK. 255-268.

Burkert, M., Davila, A., Mehta, K. \& Oyon, D. 2014. Relating Alternative Forms of Contingency Fit to the Appropriate Methods to Test Them. Management Accounting Research , 25, 6-29.

Burns, T. \& Stalker, G.M. 1961. The Management of Innovation, London, Tavistock.

Chapman, C.S. 1997. Reflections on a Contingent View of Accounting. Accounting, Organizations and Society, 22(2), 189-205.

Chenhall, R. 2007. Theorizing Contingencies in Management Control Systems Research in Chapman, C.S., Hopwood, A.G. \& Shields, M.D., Handbook of Management Accounting Research, Elsevier, 163-205.

Collier, P.M. 2005. Entrepreneurial control and the construction of a relevant accounting. Management Accounting Research, 2005, 16(3), 321-339.

Coates, J.B., Davies, E.W., Emmanuel, C.R., Longden, S.G \& Stacey, R.J. 1992. Multinational companies performance measurement systems: international The contingency theory of management accountingperspectives. Management Accounting Research, 3(2), 133-150.

Dekker, H. (this issue)

Demartini, M.C. 2011. The effectiveness of loosely coupled performance management systems and the link with innovation. Empirical evidence. Ph.D. thesis, University of Pavia, Italy.

Ferreira, A. \& Otley, D. 2009. The design and use of performance management systems: an extended framework for analysis. Management Accounting Research, 20,4, 263-282.

Fisher, J. G., 1995. Contingency-Based Research on Management Control Systems: Categorization by Level of Complexity. Journal of Accounting Literature, 14, 24-53.

Gong, M. \& Ferreira, A. 2014. Does consistency in management control system choices influence firm performance? An empirical analysis. Accounting and Business Research, 44(5), 497-522.

Grabner, I. and Moers, F. 2013. Management control as a system or a package? Conceptual and empirical issues. Accounting, Organizations and Society, 38, 407419.

Gupta, A.K \& Govindarajan, V. 1984. Business Unit Strategy, Managerial Characteristics, and Business Unit Effectiveness at Strategy Implementation. The Academy of Management Journal, 27(1), 25-41.

Hall, M. (this issue) 
Hartmann, F.G.H. \& Moers, F. 2003. Testing contingency hypotheses in budgetary research using moderated regression analysis: a second look. Accounting, Organizations and Society, 2003, 28(7), 803-809.

Hofstede, G. 1980. Culture's Consequences: international differences in work-related values. Beverly Hills, CA, Sage Publications.

Hope, J. and Fraser, R. 2003. Beyond budgeting : how managers can break free from the annual performance trap. Boston, MA, Harvard Business School Press.

Hopwood, A.G. 1972. An Empirical Study of the Role of Accounting Data in Performance Evaluation. Journal of Accounting Research, 10, 156-182.

Hopwood, A.G. 1974. Leadership Climate and the Use of Accounting Data in Performance Evaluation. The Accounting Review, 49(3), 485-495.

Hopwood, A.G. 1974. Accounting and human behaviour. London, Haymarket Publishing.

Klassen, M. 2014. Value Logics and Management Control Systems. PhD thesis, Lancaster University, UK.

Langfield-Smith, K. 1997. Management Control Systems and Strategy. Accounting, Organizations and Society, 22(2), 207-232.

Malmi, T. \& Brown, D.A. 2008. Management Control Systems as a Package Opportunities, Challenges and Research Directions. Management Accounting Research, 19, 287-300.

Miles, R.W. \& Snow, C.C. 1978. Organization Strategy, structure and process. New York, NY. McGraw-Hill.

Mundy, J. 2015. Loose Coupling and Beyond: An investigation of the Inter-relations between Management Controls. Working paper, University of Greenwich presented at BAFA conference March 2015, Manchester.

Nixon, W.A.J. \& Burns, J. 2005. Management Control in the $21^{\text {st }}$ Century, Editorial Introduction to Special Issue of Management Accounting Research, 16, 260-268.

Orton, J. and Weick, K. 1990. Loosely Coupled Systems: A Reconceptualization. The Academy of Management Review, 15(2), 203-223.

Otley, D. 1978. Budget Use and Managerial Performance. Journal of Accounting Research, 16, 122-149.

Otley, D. 1994. Management Control in Contemporary Organizations: Towards a Wider Framework. Management Accounting Research, 5, 289-299.

Otley, D. 2014. Management Control under Uncertainty: Thinking about Uncertainty. Chapter 6 in Otley, D. \& Soin, K., Management Control and Uncertainty, Palgrave Macmillan, Basingstoke, UK. 83-96.

Otley, D. \& Soin, K. 2014. Management Control and Uncertainty, Palgrave Macmillan, Basingstoke, UK.

Otley, D. and Fakiolis, A. 2000. Reliance on Accounting Performance Measures: Dead End or New Beginning? Accounting, Organizations and Society, 25, 479-510. 
Porter, M.E. 1980. Competitive Strategy. New York, NY. The Free Press.

Sandelin, M. 2008. Operation of management control practices as a package-A case study on control system variety in a growth firm context. Management Accounting Research, 19, 324-343.

Saulpic, O. and Zarlowski, P. 2014. Management Control Research and the Management of Uncertainty: Rethinking Knowledge in Management. Chapter 14 in Otley, D. \& Soin, K., Management Control and Uncertainty, Palgrave Macmillan, Basingstoke, UK. 207-223..

Simons, R. 1995. Levers of control : how managers use innovative control systems to drive strategic renewal . Boston, MA. Harvard Business School Press.

Specklé, R. and Kruis, A. 2014. Management Control Research: A Review of Current Developments. Chapter 3 in Otley, D. \& Soin, K., Management Control and Uncertainty, Palgrave Macmillan, Basingstoke, UK. 30-46.

Stabell, C. and Fjeldstad,F. 1998. Configuring Value for Competitive Advantage:

On Chains, Shops, and Networks. Strategic Management Journal, 413-437.

Tessier, S. \& Otley, D. 2012. A conceptual development of Simons' Levers of Control framework. Management Accounting Research, 23, 171-185. 


\section{Appendix A: Bibliography for review of the contingency theory of management accounting and control: 1980-2014}

Abdel-Kader, M. \& Luther, R. 2008. The impact of firm characteristics on management accounting practices: A UK- based empirical analysis. The British Accounting Review, 40, 2- 27.

Abdel-Maksoud, A., Cerbioni, F., Ricceri, F. \& Velayutham, S. 2010. Employee morale, non- financial performance measures, deployment of innovative managerial practices and shop- floor involvement in Italian manufacturing firms. The British Accounting Review, 42, 36-55.

Abernethy, M. A. \& Stoelwinder, J. U. 1991. Budget use, task uncertainty, system goal orientation and subunit performance: A test of the 'fit' hypothesis in not-for- profit hospitals. Accounting, Organizations and Society, 16, 105-120.

Abernethy, M. A. \& Guthrie, C. H. 1994. an empirical assessment of the "fit" between strategy and management information system design. Accounting \& Finance, 34, 4966.

Abernethy, M.A. \& Brownell, P. 1997. Management control systems in research and development organizations: The role of accounting, behavior and personnel controls. Accounting, Organizations and Society, 22(3), 233-248.

Abernethy, M. A. \& Brownell, P. 1999. The role of budgets in organizations facing strategic change: an exploratory study. Accounting, Organizations and Society, 24(3), 189-204.

Abernethy, M. A., Lillis, A. M., Brownell, P, \& Carter, P. 2001. Product diversity and costing system design choice: field study evidence. Management Accounting Research, 12(3), 261-279.

Abernethy, M. \& Bouwens, J. 2005. Determinants of accounting innovation implementation. Abacus. 41(3), 217-240.

Abul-Ezz, M. E. \& Dickhaut, J. W. 1993. Incentive structure and group performance expectations in a budgeting setting: A descriptive study. Accounting, Auditing \& Accountability Journal, 6(2), 1-16.

Adler, N. J. 1983. Cross- Cultural Management Research: The Ostrich and the Trend. The Academy of Management Review, 8, 226-232.

Adler, N. J. 1986. From the Atlantic to the Pacific Century: Cross- Cultural Management Reviewed. Journal of Management, 12, 295-318

Adler, R. W. 2011. Performance management and organizational strategy: How to design systems that meet the needs of confrontation strategy firms. The British Accounting Review, 43, 251-263.

Agbejule, A. 2005. The relationship between management accounting systems and perceived environmental uncertainty on managerial performance: $A$ research note. Accounting and Business Research, 35(4), 295-305. 
Agbejule, A. \& Saarikoski, L. 2006. The effect of cost management knowledge on the relationship between budgetary participation and managerial performance. The British Accounting Review, 38, 427-440.

Aguinis, H. 2002. Estimation of interaction effects in organization studies. Organizational Research Methods, 5, 207-211.

Al-Omiri, M. \& Drury, C. 2007. A survey of factors influencing the choice of product costing systems in UK organizations. Management Accounting Research, 18, 399424.

Alam, M. 1997. Budgetary process in uncertain contexts: a study of state- owned enterprises in Bangladesh. Management Accounting Research, 8, 147-167.

Albu, N. 2012. Factors Associated with the Adoption and Use of Management Accounting Techniques in Developing Countries: The Case of Romania. Journal of International Financial Management \& Accounting, 23, 245-276.

Anant, R. N. 1983. Cross-Cultural Management Research: Trend and Future Directions. Journal of International Business Studies, 14, 17.

Anderson, S. W. \& Lanen, W. N. 1999. Economic transition, strategy and the evolution of management accounting practices: the case of India. Accounting, Organizations and Society, 24, 379-412.

Anderson, S. W. \& Young, S. M. 1999. The impact of contextual and process factors on the evaluation of activity-based costing systems. Accounting, Organizations and Society, 24(7), 525-559.

Archer, S. \& Otley, D. 1991. Strategy, structure, planning and control systems and performance evaluation - Rumenco Ltd. Management Accounting Research, 2, 263303.

Arjaliès, D.L. \& Mundy, J. 2013. The use of management control systems to manage CSR strategy: A levers of control perspective. Management Accounting Research, 24, 284-300.

Auzair, S. M. \& Langfield S. K. 2005. The effect of service process type, business strategy and life cycle stage on bureaucratic MCS in service organizations. Management Accounting Research, 16, 399-421.

Awasthi, V. N., Chow, C. W. \& Wu, A. 1998. Performance measure and resource expenditure choices in a teamwork environment: the effects of national culture. Management Accounting Research, 9, 119-138.

Baines, A. \& Langfield S. K. 2003. Antecedents to management accounting change: A structural equation approach. Accounting, Organizations and Society. 28(7),675-698.

Beaubien, L. 2013. Technology, change, and management control: a temporal perspective. Accounting Audit and Accountability, 26, 48-74.

Bechor, T., Neumann, S., Zviran, M. \& Glezer, C. 2010. A contingency model for estimating success of strategic information systems planning. Information \& Management, 47, 17-29. 
Berry, A., Loughton, E. \& Otley, D. 1991. Control in a financial services company ( RIF): a case study. Management Accounting Research, 2, 109-139.

Berry, A. J., Coad, A. F., Harris, E. P., Otley, D. T. \& Stringer, C. 2009. Emerging themes in management control: A review of recent literature. The British Accounting Review, 41, 2-20.

Bhimani, A. \& Langfield-Smith, K. 2007. Structure, formality and the importance of financial and non- financial information in strategy development and implementation. Management Accounting Research, 18, 3-31.

Birkinshaw, J., Nobel, R. \& Ridderstrale, J. 2002. Knowledge as a contingency variable: Do the characteristics of knowledge predict organization structure? Organization Science, 13, 274-289.

Birnbaum, P. H. 1985. Organizational Structure of Multinational Banks in Hong Kong from a Culture- Free Perspective. Administrative Science Quarterly, 30, 262-277.

Birnberg, J. G. \& Snodgrass, C. 1988. Culture and control: A field study. Accounting, Organizations and Society, 13, 447-464.

Bonner, S. E. \& Sprinkle, G. B. 2002. The effects of monetary incentives on effort and task performance: theories, evidence, and a framework for research. Accounting, Organizations and Society, 27, 303-345.

Boyd, B. K., Takacs Haynes, K., Hitt, M. A., Bergh, D. D. \& Ketchen, D. J. 2012. Contingency Hypotheses in Strategic Management Research. Journal of Management, 38, 278-313.

Brandau, M., Hoffjan, A. \& Woempener, A. 2014. The globalization of a profession: comparative management accounting in emerging and developed countries. European Journal of International Management, 8, 73-105.

Brewer, P. C. 1998. National culture and activity- based costing systems: a note. Management Accounting Research, 9, 241-260.

Brignall, S. 1997. A contingent rationale for cost system design in services. Management Accounting Research, 8, 325-346.

Bromwich, M. 1990. The case for strategic management accounting: The role of accounting information for strategy in competitive markets. Accounting, Organizations and Society, 15(1), 27-46.

Brownell, P. 1981. Participation in Budgeting, Locus of Control and Organizational Effectiveness. The Accounting Review, 56(4), 844-860.

Brownell, P. 1982. The Role of Accounting Data in Performance Evaluation, Budgetary Participation, and Organizational Effectiveness. Journal of Accounting Research, 20(1), 12-27.

Brownell, P. 1985. Budgetary Systems and the Control of Functionally Differentiated Organizational Activities. Journal of Accounting Research, 23(2), 502-512. 
Brownell, P. \& Merchant, K. A. 1990. The Budgetary and Performance Influences of Product Standardization and Manufacturing Process Automation. Journal of Accounting Research, 28(2), 388-397.

Brownell, P. \& Dunk, A. S. 1991. Task uncertainty and its interaction with budgetary participation and budget emphasis: Some methodological issues and empirical investigation. Accounting, Organizations and Society, 1991, 16(8), 693-703.

Budding, G. T. 2004. Accountability, environmental uncertainty and government performance: evidence from Dutch municipalities. Management Accounting Research, 15, 285-304.

Byrne 2010. Testing for measurement and structural equivalence in large-scale crosscultural studies: Addressing the issue of non-equivalence. International Journal of Testing, 10(2), 107-132.

Byrne, S. \& Damon, F. 2008. To participate or not to participate? Voice and explanation effects on performance in a multi-period budget setting. The British Accounting Review, 40, 207-227.

Byrne, S. \& Pierce, B. 2007. Towards a more comprehensive understanding of the roles of management accountants. European Accounting Review, 16, 469-498.

Cadez, S. \& Guilding, C. 2008. An exploratory investigation of an integrated contingency model of strategic management accounting. Accounting Organizations and Society, 33, 836- 863.

Carpenter, M. A. \& Sanders, W. G. 2004. The effects of top management team pay and firm internationalization on MNC performance. Journal of Management, 30, 509528.

Carr, C., Kolehmainen, K. \& Mitchell, F. 2010. Strategic investment decision making practices: A contextual approach. Management Accounting Research, 21, 167-184.

Carr, C. \& Tomkins, C. 1998. Context, culture and the role of the finance function in strategic decisions. A comparative analysis of Britain, Germany, the U.S.A. and Japan. Management Accounting Research, 9, 213-239.

Cescon, F. 2012. the impact of AMT firm characteristics on innovative costing techniques and non-financial measures of performance. In: Davila, A., Epstein, M. J. \& Manzoni, J. F. (eds.) Performance Measurement and Management Control: Global Issues.

Chang, R. D., Chang, Y. W. \& Paper, D. 2003. The effect of task uncertainty, decentralization and AIS characteristics on the performance of AIS: an empirical case in Taiwan. Information \& Management, 40, 691-703.

Chapman, C. S. 1997. Reflections on a contingent view of accounting. Accounting, Organizations and Society, 22, 189-205.

Chenhall, R. \& Langfield-Smith, K. 1998. Factors influencing the role of management accounting in the development of performance measures within organizational change programs. Management Accounting Research, 9(4), 361-386. 
Chenhall, R. H. 2003. Management control systems design within its organizational context: findings from contingency-based research and directions for the future. Accounting, Organizations and Society, 28, 127-168.

Chenhall, R. H. 2012. Developing an Organizational Perspective to Management Accounting. Journal of Management Accounting Research., 24(1), 65-76.

Chenhall, R. H., Kallunki, J.-P. \& Silvola, H. 2011. Exploring the Relationships between Strategy, Innovation, and Management Control Systems: The Roles of Social Networking, Organic Innovative Culture, and Formal Controls. Journal of Management Accounting Research, 23(1), 99-128.

Chenhall, R. H. \& Morris, D. 1986. The Impact of Structure, Environment, and Interdependence on the Perceived Usefulness of Management Accounting Systems. The Accounting Review, 61(1), 16-35.

Chenhall, R. H. \& Smith, D. 2011. A review of Australian management accounting research: 1980-2009. Accounting and Finance, 51, 173-206.

Chesley, G. R. 1984. The Financial Reporting of Contingencies and Uncertainties: Theory and Practice ( Book Review). The Accounting Review, 59(4), pp.716-717

Chong, M. L., Liang, C. L. \& lan, R. C. E. 1997. The interactive effect of budget emphasis, participation and task difficulty on managerial performance: a crosscultural study. Accounting, Auditing \& Accountability Journal, 10, 175-197.

Chong, V. \& Chong, K. M. 1997. Strategic Choices, Environmental Uncertainty and SBU Performance: A Note on the Intervening Role of Management Accounting Systems. Accounting and Business Research, 27, 268-276.

Chong, V. \& Johnson, D. 2007. Testing a model of the antecedents and consequences of budgetary participation on job performance. Accounting and Business Research, 37(1), 3-19.

Chong, V. K. 1998. Testing the contingency "fit" between management accounting systems and managerial performance: a research note on the moderating role of tolerance for ambiguity. The British Accounting Review, 30, 331-342.

Chong, V. K., Eggleton, I. R. C. \& Leong, M. K. C. 2005. The impact of market competition and budgetary participation on performance and job satisfaction: a research note. The British Accounting Review, 37, 115-133.

Chong, V. K. \& Rundus, M. J. 2004. Total quality management, market competition and organizational performance. The British Accounting Review, 36, 155-172.

Chow, C. W., Kato, Y. \& Shields, M. D. 1994. National culture and the preference for management controls: An exploratory study of the firm- Labor market interface. Accounting, Organizations and Society, 19, 381-400.

Chow, C. W., Shields, M. D. \& Chan, Y. K. 1991. The effects of management controls and national culture on manufacturing performance: An experimental investigation. Accounting, Organizations and Society, 16, 209-226. 
Chow, C. W., Shields, M. D. \& Wu, A. 1999. The importance of national culture in the design of and preference for management controls for multi-national operations. Accounting, Organizations and Society, 24, 441-461.

Connor, N. G. 1995. The influence of organizational culture on the usefulness of budget participation by Singaporean- Chinese managers. Accounting, Organizations and Society, 20, 383-403.

Covaleski, M. A., Dirsmith, M. W. \& Samuel, S. 1996. Managerial accounting research: The contributions of organizational and sociological theories. Journal of Management Accounting Research, 8, 1-36.

Covaleski, M. A., Evans, J. H., Luft, J. L. \& Shields, M. D. 2003. Budgeting Research: Three Theoretical Perspectives and Criteria for Selective Integration. Journal of Management Accounting Research, 15(1), 3-49.

Cugueró-Escofet, N. \& Rosanas, J. M. 2012. The just design and use of management control systems as requirements for goal congruence. Management Accounting Research, 24(1), 23- 40.

Derfuss, K. 2009. The Relationship of Budgetary Participation and Reliance on Accounting Performance Measures with Individual-Level Consequent Variables: A Meta-Analysis. European Accounting Review, 18, 203-239.

Deville, A., Ferrier, G. D. \& Leleu, H. 2014. Measuring the performance of hierarchical organizations: An application to bank efficiency at the regional and branch levels. Management Accounting Research, 25, 30-44.

Ditillo, A. 2004. Dealing with uncertainty in knowledge- intensive firms: the role of management control systems as knowledge integration mechanisms. Accounting, Organizations and Society, 29, 401-421.

Donaldson, L. 1987. Strategy and structural adjustment to regain fit and performance: in defence of contingency theory. Journal of Management Studies, 24(1), 1-24.

Donaldson, L. 2001. The contingency theory of organizations, Thousand Oaks, Calif., Thousand Oaks, Calif. : Sage.

Dossi, A. \& Patelli, L. 2008. The decision- influencing use of performance measurement systems in relationships between headquarters and subsidiaries. Management Accounting Research, 19, 126-148.

Drazin, R. \& Van De Ven, A. H. 1985. Alternative Forms of Fit in Contingency Theory. Administrative Science Quarterly, 30(4), 514-39.

Duh, R. R., Xiao, J. Z. \& Chow, C. W. 2008. An Overview and Assessment of Contemporary Management Accounting Research in China. Journal of Management Accounting Research., 20(s1), 129-164.

Dunk, A. S. 1992. The effects of managerial level on the relationship between budgetary participation and job satisfaction. The British Accounting Review, 24, 207218. 
Dunk, A. S. 2003. Moderated regression, constructs and measurement in management accounting: a reflection. Accounting, Organizations and Society, 28, 793-802.

Dunk, A. S. 2011. Product innovation, budgetary control, and the financial performance of firms. The British Accounting Review, 43, 102-111.

Efferin, S. \& Hopper, T. 2007. Management control, culture and ethnicity in a Chinese Indonesian company. Accounting, Organizations and Society, 32, 223-262.

Elg, M. \& Kollberg, B. 2009. Alternative arguments and directions for studying performance measurement. Total Quality Management \& Business Excellence, 20, 409-421.

Emsley, D. 2001. Redesigning variance analysis for problem solving. Management Accounting Research, 12, 21-40.

Evans, J. H., Lewis, B. L. \& Patton, J. M. 1986. An economic modelling approach to contingency theory and management control. Accounting, Organizations and Society, $11,483-498$.

Ewusi-Mensah 1981. The external organizational environment and its impact on managerial information systems. Accounting, Organizations and Society, 6(4), 301316.

Ezzamel, M. 1990. The impact of environmental uncertainty, managerial autonomy and size on budget characteristics. Management Accounting Research, 1, 181-197.

Ferreira, A. \& Otley, D. 2009. The design and use of performance management systems: An extended framework for analysis. Management Accounting Research, 20, 263-282.

Fisher, C. 1996. The impact of perceived environmental uncertainty and individual differences on management information requirements: A research note. Accounting, Organizations and Society, 21, 361-369.

Frank, H. M. V. 2008. Performance management practices in public sector organizations; Impact on performance. Accounting, Auditing \& Accountability Journal, $21,427-454$.

Frow, N., Marginson, D. \& Ogden, S. 2005. Encouraging strategic behaviour while maintaining management control: Multi- functional project teams, budgets, and the negotiation of shared accountabilities in contemporary enterprises. Management Accounting Research, 16, 269-292.

Fullerton, R. R., Kennedy, F. A. \& Widener, S. K. 2012. Management accounting and control practices in a lean manufacturing environment. Accounting, Organizations and Society, 38(1), 50-71.

G.M. Cunningham. 1992. Management Control and Accounting Systems Under a Competitive Strategy. Accounting, Auditing \& Accountability Journal, 5(2), 36-57.

Garengo, P. \& Bititci, U. 2007. Towards a contingency approach to performance measurement: an empirical study in Scottish SMEs. International Journal of Operations \& Production Management, 27, 802-825. 
Gerdin, J. 2005a. Management accounting system design in manufacturing departments: an empirical investigation using a multiple contingencies approach. Accounting, Organizations and Society, 30, 99-126.

Gerdin, J. 2005b. The Impact of departmental interdependencies and management accounting system use on subunit performance. European Accounting Review, 14, 297-327.

Gerdin, J. \& Greve, J. 2004. Forms of contingency fit in management accounting research - a critical review. Accounting Organizations and Society, 29, 303-326.

Gerdin, J. \& Greve, J. 2008. The appropriateness of statistical methods for testing contingency hypotheses in management accounting research. Accounting Organizations and Society, 33, 995-1009.

Giroux, G. A., Mayper, A. G. \& Daft, R. L. 1986. Organization size, budget cycle, and budget related influence in city governments: An empirical study. Accounting, Organizations and Society, 11, 499-519.

Goddard, A. 1997. Organisational Culture and Budgetary Control in a UK Local Government Organisation. Accounting and Business Research, 27, 111-123.

Gordon, L. A. \& Narayanan, V. K. 1984. Management accounting systems, perceived environmental uncertainty and organization structure: An empirical investigation. Accounting, Organizations and Society, 9, 33-47.

Govindarajan, V. 1984. Appropriateness of accounting data in performance evaluation: An empirical examination of environmental uncertainty as an intervening variable. Accounting, Organizations and Society, 9, 125-135.

Govindarajan, V. 1986. Impact of participation in the budgetary process on managerial attitudes and performance: Decision Sciences.

Govindarajan, V. 1988. A Contingency Approach to Strategy Implementation at the Business- Unit Level: Integrating Administrative Mechanisms with Strategy. Academy of Management Journal, 31(4),828-853.

Granlund, M. 2003. Management accounting system integration in corporate mergers: A case study. Accounting, auditing \& accountability journal., 16(2), 208-243.

Granlund, M. \& Lukka, K. 1998. Towards increasing business orientation: Finnish management accountants in a changing cultural context. Management Accounting Research, 9, 185-211.

Gul, F. 1991. The Effects of Management Accounting Systems and Environmental Uncertainty on Small Business Managers' Performance. Accounting and Business Research, 22, 57-61.

Gul, F., Tsui, J. S. L., Fong, S. C. C. \& Kwok, H. Y. L. 1995. Decentralisation as a Moderating Factor in the Budgetary Participation-Performance Relationship: Some Hong Kong Evidence. Accounting and Business Research, 25, 107-113. 
Gul, F. A. \& Chia, Y. M. 1994. The effects of management accounting systems, perceived environmental uncertainty and decentralization on managerial performance: A test of three- way interaction. Accounting, Organizations and Society, 19, 413-426.

Haka, S. F. 1987. Capital budgeting techniques and firm specific contingencies: A correlational analysis. Accounting, Organizations and Society, 12, 31-48.

Haldma, T. \& Lääts, K. 2002a. Contingencies influencing the management accounting practices of Estonian manufacturing companies. Management Accounting Research, 13, 379- 400.

Haldma, T. \& Lääts, K. 2002b. Contingencies influencing the management accounting practices of Estonian manufacturing companies. Management Accounting Research, 13(4),379-400.

Hana et al. 2010. Cross-country study on the effects of national culture on earnings management. Journal of international business studies, 41(1),123-141.

Hansen, S. C., Otley, D. T. \& Van Der Stede, W. A. 2003. Practice Developments in Budgeting: An Overview and Research Perspective. Journal of Management Accounting Research, 15, 95-116.

Harrison, G. L. 1992. The cross- cultural generalizability of the relation between participation, budget emphasis and job related attitudes. Accounting, Organizations and Society, 17, 1-15.

Harrison, G. L. 1993. Reliance on accounting performance measures in superior evaluative style - The influence of national culture and personality. Accounting, Organizations and Society, 18, 319-339.

Harrison, G. L. \& Mckinnon, J. L. 1999. Cross- cultural research in management control

systems design: a review of the current state. Accounting, Organizations and Society, 24, 483-506.

Harrison, G. L., Mckinnon, J. L., Panchapakesan, S. \& Leung, M. 1994. The Influence of Culture on Organizational Design and Planning and Control in Australia and the United States Compared with Singapore and Hong Kong. Journal of International Financial Management \& Accounting, 5, 242-261.

Hartmann, F. \& Slapnicar, S. 2012. The perceived fairness of performance evaluation: The role of uncertainty. Management Accounting Research, 23, 17-33.

Hartmann, F. G. H. \& Moers, F. 1999. Testing contingency hypotheses in budgetary research: an evaluation of the use of moderated regression analysis. Accounting Organizations and Society, 24, 291-315.

Hartmann, F. G. H. \& Moers, F. 2003. Testing contingency hypotheses in budgetary research using moderated regression analysis: a second look. Accounting Organizations and Society, 28, 803-809.

Hartmann, F. H. 2005. The impact of departmental interdependencies and management accounting system use on subunit performance: A comment. European Accounting Review, 14, 329-334. 
Hawawini, G., Subramanian, V. \& Verdin, P. 2003. Is performance driven by industryor firm-specific factors? A new look at the evidence. Strategic Management Journal, 24(1), 1- 16.

Henri, J.-F. 2006. Organizational culture and performance measurement systems. Accounting, Organizations and Society, 31, 77-103.

Henri, J.-F. 2010. The Periodic Review of Performance Indicators: An Empirical Investigation of the Dynamism of Performance Measurement Systems. European Accounting Review, 19, 73-96.

Higgins, S. T. 2010. Comments on contingency management and conditional cash transfers. Health Economics, 19, 1255-1258.

Ho, J. L. Y., Wu, A. \& Wu, S. Y. C. 2014. Performance measures, consensus on strategy implementation, and performance: Evidence from the operational- level of organizations. Accounting, Organizations and Society, 39, 38-58.

Hoozee, S. \& Bruggernan, W. 2010. Identifying operational improvements during the design process of a time- driven $\mathrm{ABC}$ system: The role of collective worker participation and leadership style. Management Accounting Research, 21, 185-198.

Hopper, T., Otley, D. \& Scapens, B. 2001. British Management Accounting Research: Whence and Whither: Opinions and Recollections. The British Accounting Review, 33, 263- 291.

Hoque, Z. 2004. A contingency model of the association between strategy, environmental uncertainty and performance measurement: impact on organizational performance. International Business Review, 13(4), 485-502.

Hoque, Z. 2005. Linking environmental uncertainty to non- financial performance measures and performance: a research note. The British Accounting Review, 37, 471481.

Hoque, Z. \& Hopper, T. 1997. Political and Industrial Relations Turbulence, Competition and Budgeting in the Nationalised Jute Mills of Bangladesh. Accounting and Business Research, 27, 125-143.

Hoque, Z. \& James, W. 2000. Linking balanced scorecard measures to size and market factors: Impact on organizational performance. Journal of Management Accounting Research, 12(1), 1-17.

House, R. J.2004 Global leadership and organizational behavior effectiveness research, in Culture, leadership, and organizations : the GLOBE study of 62 societies, Thousand Oaks, Calif., Thousand Oaks, Calif. : Sage Publications

Hyvönen, J. 2007. Strategy, performance measurement techniques and information technology of the firm and their links to organizational performance. Management Accounting Research, 18, 343-366.

Imoisili, O. A. 1989. The role of budget data in the evaluation of managerial performance. Accounting, Organizations and Society, 14, 325-335.

Innes, J. \& Mitchell, F. 1990. The process of change in management accounting: some field study evidence. Management Accounting Research, 1, 3-19. 
Ittner, C. D. \& Larcker, D. F. 1997. Quality strategy, strategic control systems, and organizational performance. Accounting, Organizations and Society, 22, 293-314.

Jansen, E. P. 2011. The effect of leadership style on the information receivers' reaction to management accounting change. Management Accounting Research, 22, 105-124.

Jermias, J. 2008. The relative influence of competitive intensity and business strategy on the relationship between financial leverage and performance. The British

Accounting Review, 40, 71-86.

Jermias, J. \& Gani, L. 2004. Integrating business strategy, organizational configurations and management accounting systems with business unit effectiveness: a fitness landscape approach. Management Accounting Research, 15, 179-200.

John D. M. \& Esam, M. 2013. An exploratory analysis of management accounting practices in the Arab Gulf Cooperative countries. Journal of Islamic Accounting and Business Research, 4, 51-63.

Kallunki, J. P. \& Silvola, H. 2008. The effect of organizational life cycle stage on the use of activity- based costing. Management Accounting Research, 19, 62-79.

Kennedy, F. A. \& Widener, S. K. 2008. A control framework: Insights from evidence on lean accounting. Management Accounting Research, 19, 301-323.

Kihn, L. 2007. Financial Consequences in Foreign Subsidiary Manager Performance Evaluations. Accounting in Europe., 16(3), 531-554.

King, R., Clarkson, P. M. \& Wallace, S. 2010. Budgeting practices and performance in small healthcare businesses. Management Accounting Research, 21, 40-55.

Kober, R., NG, J. \& Paul, B. J. 2007. The interrelationship between management control mechanisms and strategy. Management Accounting Research, 18, 425-452.

Kominis, G. \& Dudau, A. I. 2012. Time for interactive control systems in the public sector? The case of the Every Child Matters policy change in England. Management Accounting Research, 23, 142-155.

Kristensen, T. B. \& Israelsen, P. 2014. Performance effects of multiple control forms in a Lean organization: A quantitative case study in a systems fit approach.

Management Accounting Research, 25, 45-62.

Lachman, R., Nedd, A. \& Hinings, B. 1994. Analyzing Cross- National Management and Organizations: A Theoretical Framework. Management Science, 40, 40-55.

Lau, C. M. 1999. the effect of emphasis on tight budget targeits and cost control on production and marketing managers' propensity to create slack. The British Accounting Review, 31, 415- 437.

Lau, C. M. \& Lim, E. W. 2002. The intervening effects of participation on the relationship between procedural justice and managerial performance. The British Accounting Review, 34, 55-78. 
Lau, C. M., Low, L. C. \& Eggleton, I. R. C. 1995. The impact of reliance on accounting performance measures on job-related tension and managerial performance:

Additional evidence. Accounting, Organizations and Society, 20, 359-381.

Lau, C. M. \& Tan, J. J. 1998. The impact of budget emphasis, participation and task difficulty on managerial performance: a cross-cultural study of the financial services sector. Management Accounting Research, 9, 163-183.

Leach-López, M. A., Stammerjohan, W. W. \& Mcnair, F. M. 2007. Differences in the Role of Job-Relevant Information in the Budget Participation-Performance Relationship among U.S. and Mexican Managers: A Question of Culture or Communication. Journal of Management Accounting Research, 105-136, 105-136.

Lee, C. L. \& Yang, H. J. 2011. Organization structure, competition and performance measurement systems and their joint effects on performance. Management Accounting Research, 22, 84-104.

Lee, J. \& Miller, D. 1996. Strategy, Environment and Performance in Two Technological Contexts: Contingency Theory in Korea. Organization Studies, 17, 729750.

Li, P. L. \& Tang, G. L. 2009. Performance measurement design within its organizational context- Evidence from China. Management Accounting Research, 20, 193-207.

Lillis, A. M. \& Van Veen-dirks, P. M. G. 2008. Performance Measurement System Design in Joint Strategy Settings. Journal of Management Accounting Research, 20, 25-57.

Llewellyn, S. 1994. Managing the boundary: How accounting is implicated in maintaining the organization. Accounting, Auditing \& Accountability Journal., 7(4), 423.

Llewellyn, S. 2003. What counts as "theory" in qualitative management and accounting research? Introducing five levels of theorizing. Accounting, Auditing \& Accountability Journal, 16, 662-708.

Luther, R. G. \& Longden, S. 2001. Management accounting in companies adapting to structural change and volatility in transition economies: a South African study. Management Accounting Research, 12, 299-320.

Macintosh, N. B. 2010. Management accounting and control systems : an organizational and sociological approach, Chichester, Chichester : Wiley.

Malina, M. A. \& Selto, F. H. 2004. Choice and change of measures in performance measurement models. Management Accounting Research, 15, 441-469.

Merchant, K. A. 1981. The Design of the Corporate Budgeting System: Influences on Managerial Behavior and Performance. The Accounting Review, 56, 813-829.

Merchant, K. A. 1984. Influences on departmental budgeting: an empirical examination of a contingency model. Accounting, Organizations and Society, 9, 291307. 
Merchant, K. A., Chow, C. W. \& Wu, A. 1995. Measurement, evaluation and reward of profit center managers: A cross- cultural field study. Accounting, Organizations and Society, 20, 619-638.

Mia, L. 1988. Managerial attitude, motivation and the effectiveness of budget participation. Accounting, Organizations and Society, 13, 465-475.

Mia, L. 1989. The impact of participation in budgeting and job difficulty on managerial performance and work motivation: A research note. Accounting, Organizations and Society, 14, 347-357.

Moores, K. \& Yuen, S. 2001. Management accounting systems and organizational configuration: a life-cycle perspective. Accounting Organizations and Society, 26, 351389.

Naranjo-Gil, D. \& Hartmann, F. 2007. Management accounting systems, top management team heterogeneity and strategic change. Accounting Organizations and Society, 32, 735-756.

Naranjo-Gil, D., Maas, V. S. \& Hartmann, F. G. H. 2009. How CFOs Determine Management Accounting Innovation: An Examination of Direct and Indirect Effects. European Accounting Review, 18, 667-695.

Naranjo-Gil, D. \& Hartmann, F. 2006. How Top Management Teams Use Management Accounting Systems to Implement Strategy. Journal of Management Accounting Research, 18(1), 21-53.

Nava, S. \& Lokman, M. 2001. The relation between decentralised structure, budgetary participation and organisational commitment; The moderating role of managers' value orientation towards innovation. Accounting, Auditing \& Accountability Journal, 14, 12-30.

Nelson, M. W. \& Kinney, W. R. 1997. The Effect of Ambiguity on Loss Contingency Reporting Judgments. The Accounting Review, 72, 257-274.

Nixon, W. A. J. \& Burns, J. 2005. Management control in the 21st century. Management Accounting Research, 2005, Vol.16(3), pp.260-268

Ortega, C. H., Garrido-vega, P. \& Dominguez Machuca, J. A. 2012. Analysis of interaction fit between manufacturing strategy and technology management and its impact on performance. International Journal of Operations \& Production Management, 32, 958-981.

Otley, D. T. 1980. The contingency theory of management accounting: Achievement and prognosis. Accounting, Organizations and Society, 5, 413-428.

Otley, D. 1999. Performance management: a framework for management control systems research. Management Accounting Research, 10, 363-382.

Pennings, J. M. 1975. The Relevance of the Structural- Contingency Model for Organizational Effectiveness. Administrative Science Quarterly, 20, 393-410.

Pertusa-Ortega, E. M., Molina-Azorin, J. F. \& Claver-Cortes, E. 2010. Competitive strategy, structure and firm performance A comparison of the resource-based view and the contingency approach. Management Decision, 48, 1282-1303. 
Pettersen, I. J. 2004. From bookkeeping to strategic tools?: A discussion of the reforms in the Nordic hospital sector. Management Accounting Research, 15, 319335.

Qian, W., Burritt, R. \& Monroe, G. 2011. Environmental management accounting in local government A case of waste management. Accounting Auditing \& Accountability Journal, 24, 93-128.

Rankin, F. W., Schwartz, S. T. \& Young, R. A. 2003. Management Control Using Nonbinding Budgetary Announcements. Journal of Management Accounting Research., 15(1), 75-93.

Reid, G. C. \& Smith, J. A. 2000. The impact of contingencies on management accounting system development. Management Accounting Research, 11, 427-450.

Rossing, C. P. \& Rohde, C. 2010. Overhead cost allocation changes in a transfer pricing tax compliant multinational enterprise. Management Accounting Research, 21, 199-216.

Said, A. A., HassabelnabY, H. R. \& Wier, B. 2003. An Empirical Investigation of the Performance Consequences of Nonfinancial Measures. Journal of Management Accounting Research, 15(1), 193-22.

Schoonhoven, C. B. 1981. Problems with Contingency Theory: Testing Assumptions Hidden within the Language of Contingency " Theory". Administrative Science Quarterly, 26, 349- 377.

Schoute, M. 2009. The relationship between cost system complexity, purposes of use, and cost system effectiveness. The British Accounting Review, 41, 208-226.

Schweikart, J. A. 1992. Cognitive-contingency theory and the study of ethics in accounting. Journal of Business Ethics, 11, 471-478.

Seal, W. 2010. Managerial discourse and the link between theory and practice: From $\mathrm{ROI}$ to value- based management. Management Accounting Research, 21, 95-109.

Selto, F. H., Renner, C. J. \& Young, S. M. 1995. Assessing the organizational fit of a just- in- time manufacturing system: Testing selection, interaction and systems models of contingency theory. Accounting, Organizations and Society, 20, 665-684.

Sharma, D. S. 2002. The differential effect of environmental dimensionality, size, and structure on budget system characteristics in hotels. Management Accounting Research, 13, 101-130.

Shields, J. F. \& Shields, M. D. 1998a. Antecedents and consequences of participative budgeting: Evidence on the effects of asymmetrical information. Journal of Management Accounting Research, 23(1), 49-76.

Shields, J. F. \& Shields, M. D. 1998b. Antecedents of participative budgeting. Accounting, Organizations and Society, 23(1), 49-76. 
Siti Zaleha Abdul, R., Abdul Rahim Abdul, R. \& Wan Khairuzzaman Wan, I. 2011. Management accounting systems in Islamic and conventional financial institutions in Malaysia. Journal of Islamic Accounting and Business Research, 2, 153-176.

Smith, P. B. 2005. Book Review: Culture, Leadership, and Organizations: The Globe Study of 62 Societies. Journal of Cross-Cultural Psychology, 36, 628-630.

Speckbacher, G. \& Wentges, P. 2012. The impact of family control on the use of performance measures in strategic target setting and incentive compensation: $\mathrm{A}$ research note. Management Accounting Research, 23, 34-46.

Stoel, M. D. \& Muhanna, W. A. 2009. IT capabilities and firm performance: A contingency analysis of the role of industry and IT capability type. Information \& Management, 46, 181- 189.

Thomas, A. P. 1986. The contingency theory of corporate reporting: Some empirical evidence. Accounting, Organizations and Society, 11, 253-270.

Tiessen, P. \& Waterhouse, J. H. 1983. Towards a descriptive theory of management accounting. Accounting, Organizations and Society, 8, 251-267.

Tillema, S. 2005. Towards an integrated contingency framework for MAS sophistication: Case studies on the scope of accounting instruments in Dutch power and gas companies. Management Accounting Research, 16, 101-129.

Tosi, H. L. 1984. Contingency theory: Some suggested directions. Journal of Management, 10(1), 9-26.

Van Der Meer-Kooistra, J. \& Scapens, R. W. 2008. The governance of lateral relations between and within organizations. Management Accounting Research, 19, 365-384.

Van Der Meer-Kooistra, J. \& Vosselman, E. G. J. 2000. Management control of inter firm transactional relationships: the case of industrial renovation and maintenance. Accounting, Organizations and Society, 25, 51-77.

Van Veen-Dirks, P. 2006. Complementary choices and management control: Field research in a flexible production environment. Management Accounting Research, 17, 72-105.

Venkatesh, R. \& Blaskovich, J. 2012. The Mediating Effect of Psychological Capital on the Budget Participation- Job Performance Relationship. Journal of Management Accounting Research, 24, 159-175.

Venkatraman, N. 1989. The concept of fit in strategy research: Toward verbal and statistical correspondence. The Academy of Management Review, 14(3), 423-444.

Veprauskaitè, E. \& ADAMS, M. 2013. Do powerful chief executives influence the financial performance of UK firms? The British Accounting Review, 45, 229-241.

Verbeeten, F. H. M. 2006. Do organizations adopt sophisticated capital budgeting practices to deal with uncertainty in the investment decision?: A research note. Management Accounting Research, 17, 106-120. 
Volberda, H. W., 2012. Contingency Fit, Institutional Fit, and Firm Performance: A Metafit Approach to Organization-Environment Relationships. Organization Science, 23, 1040-1054.

Waweru, N. M., Hoque, Z. \& Uliana, E. 2004. Management accounting change in South Africa: case studies from retail services. Accounting, Auditing \& Accountability Journal., 17(5), 675-704.

White, R. E. 1986. Generic Business Strategies, Organizational Context and Performance: An Empirical Investigation. Strategic Management Journal, 7(3), 217231.

Whittle, A. \& Mueller, F. 2010. Strategy, enrolment and accounting: the politics of strategic ideas. Accounting Auditing and Accountability Journal, 23, 626-646.

Widener, S. K. 2004. An empirical investigation of the relation between the use of strategic human capital and the design of the management control system. Accounting, Organizations and Society, 29, 377-399.

Widener, S. K. 2006. Associations between strategic resource importance and performance measure use: The impact on firm performance. Management Accounting Research, 17, 433- 457.

Widener, S. K. 2007. An empirical analysis of the levers of control framework. Accounting, Organizations and Society, 32, 757-788.

Williams, J. J., Macintosh, N. B. \& Moore, J. C. 1990. Budget- related behavior in public sector organizations: Some empirical evidence. Accounting, Organizations and Society, 15, 221-246.

Williams, J. J. \& Seaman, A. E. 2002. Management accounting systems change and departmental performance: the influence of managerial information and task uncertainty. Management Accounting Research, 13, 419-445.

Woods, M. 2009. A contingency theory perspective on the risk management control system within Birmingham City Council. Management Accounting Research, 20, 6981.

Wright, M. \& Thompson, S. 1987. Divestment and the Control of Divisionalised Firms. Accounting and Business Research., 17(67), 259-267.

Yin, X. \& Zajac, E. J. 2004. The strategy/ governance structure fit relationship: theory and evidence in franchising arrangements. Strategic Management Journal, 25, 365383.

Ylinen, M. \& Gullkvist, B. 2013. The effects of organic and mechanistic control in exploratory and exploitative innovations. Management Accounting Research, 25, 93112. 
Table 1. Number of articles by journal

\begin{tabular}{|l|l|}
\hline \multicolumn{1}{|c|}{ Name of the Journal } & Number \\
\hline Accounting, Organizations and Society & 66 \\
\hline Management Accounting Research & 57 \\
\hline British Accounting Review & 22 \\
\hline Journal of Management Accounting Research & 13 \\
\hline Accounting, Auditing and Accountability Journal & 9 \\
\hline European Accounting Review & 9 \\
\hline Accounting and Business Research & 7 \\
\hline Subtotal & 183 \\
\hline Information and Management & 4 \\
\hline Strategic Management Journal & 4 \\
\hline Administrative Science Quarterly & 3 \\
\hline Journal of Management & 3 \\
\hline Subtotal & 14 \\
\hline Others & 39 \\
\hline Total & 236 \\
\hline \hline
\end{tabular}


Figure 1. Number of articles on the contingency theory of management accounting by year

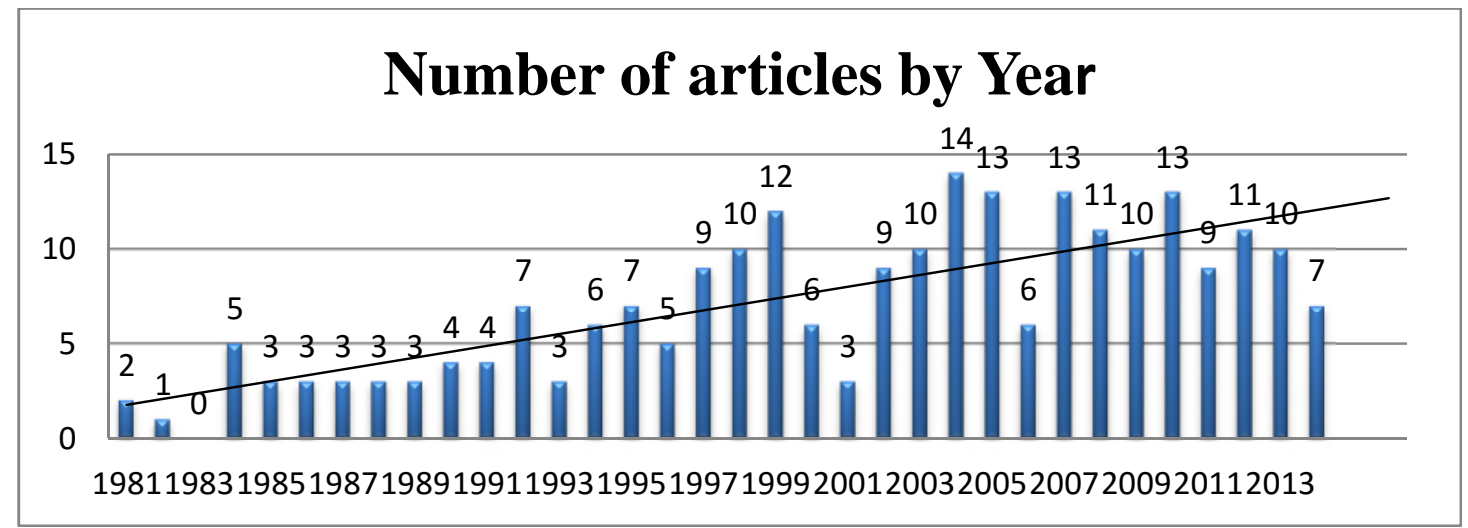

